Wir halten inne, um nicht Gedankne unserer Zeit nachzugehen, um nicht auf Möglichkeiten hinzuweisen, die aus dem Gesamtverlauf der Geschichte des deutschen Klerus als einer Schicht des Volkes überhaupt sich ergeben könnten. Nur nach rückwärts darf der Historiker als Prophet sich wenden, allein darum besorgt, daß sein Bild von der Vergangenheit als nicht ganz verfehlt befunden werde.

\title{
III. \\ Westgotischer und katholische Auszüge des sechzehnten Buchs des Theodosianus.
}

\author{
Von \\ Herm Professor Dr. Max Conrat (Cohn) \\ in Heidelberg.
}

Das für die römische Bevölkerung seines Reiches bestimmte Gesetzbuch des Westgotenkönigs Alarich II. vom Jahre 506, die Lex Romana Visigothorum (Wisigothorum) oder das sogenannte Breviarium Alaricianum, Breviar schlechthin, zuletzt von G. Haenel (L. R. V., 1849) herausgegeben (cit. 'Haenel') besteht in Auszügen aus Juristenschriften, dem Jus, insbesondere aus den Sentenzen des Paulus und aus den Institutionen des Gajus (Epitome Gai), sodann aber in Auszügen aus den Leges, den Sammlungen kaiserlicher Gesetze. Es sind dies das 16 Bücher umfassende Gesetzbuch Theodosius' II. (cit. 'Theod.') vom Jahre 438 und Sammlungen posttheodosianischer Novellen: beide werden hier nach der neuesten, die Sirmondische Konstitutionensammlung einschließenden Ausgabe (Theod. libri XVI cum constit. Sirmond. et leges Novell., 1905), Theod. (I, 2), nebst der genannten Sammlung, von Mommsen (cit. 'ed. Mommsen'), die Novellensammlungen von P. Meyer (II) (cit. 'ed. P. Meyer') benutzt ${ }^{1}$ ), die indessen nach ihrer Einrichtung, soweit der Text in das Breviar übergegangen ist, auch als Ausgabe der genannten Beviarauszüge dienen können. Das 16. Buch von

1) Hierzu kommen dann noch die von Traube herausgegebenen Tabulae sex (cit. 'Traube'). 
Theod. (cit. 'Theod. XVI') enthält Gesetze, die sich auf Religion und Kirche beziehen, so daß man ihm füglich einen kirchenrechtlichen Inhalt zuschreiben kann. Es gibt aber davon nicht lediglich einen Breviarauszug, sondern auch andere Auszüge, die überwiegend entweder zur Ergänzung des ersteren hergestellt wurden oder wenigstens nachträglich mit ihm in Verbindung getreten sind. Die Auszüge von Theod.XVI bilden dann den Gegenstand der folgenden Untersuchung. Thre Anregung verdankt sie den durch Vollständigkeit und Übersichtlichkeit ausgezeichneten, auf die Erweiterungen des Breviars aus Theod. XVI sich beziehenden Mitteilungen Mommsens in den Prolegomena seiner Ausgabe (cit. 'Mommsen? $^{3}$ (I, 1, p. LXXXVII-XCII), und ihre Förderung insbesondere Jac. Godofredus' Kommentar in seiner Ausgabe von Theod. (Cod. Theod., 1736-1745 [ed. Ritter]).

I.

1. Ich beginne mit dem Breviarauszug, der Theod. XVI, welches Buch auch hier die gleiche Stelle einnimmt, in stark verkürzter Gestalt bietet. Von elf Titeln sind fünf aufgenommen, der zweite ('De episcopis ecclesiis et clericis'), der siebente ('De apostatis'), der achte ('De Iudaeis Caelicolis et Samaritianis'), der neunte ("Ne Christianum mancipium Iudaeus habeat') und der letzte ('De religione'), die demnach im Breviar die Ziffern 1-5 führen: es fehlen somit die Titel unter den Rubriken 'De fide catholica' (1), 'De monachis' (3), 'De his qui super religione contendunt (4), 'De haereticis' (5), 'Ne sanctum baptisma iteretur' (6), 'De paganis sacrificiis et templis' (10). Von 201 Konstitutionen der Vorlage hat der Auszug nicht mehr als elf. Welches sind nun die Motive, die den westgotiscben Gesetzgeber zu dieser geradezu massenhaften Ausscheidung der Texte seiner Vorlage veranlabt haben? Es ist natürlich die gleiche Frage, die sich mit Bezug auf die Auszüge aus dem Jus erhebt: nur bietet sich hier die Möglichkeit einer vollständigen Lösung, da uns in Theod. XVI die unverkürzte Vorlage des Auszugs erhalten geblieben ist, während wir das im Breviar ausgezogene Jus zum Teil, und so auch was die Sentenzen des Paulus anlangt, lediglich fragmentarisch besitzen. ${ }^{1}$ ) An-

1) Der Verfasser hat den Versuch gemacht, sowohl mit Bezug auf 
dererseits darf man von vornherein erwarten, daB gewisse Motive, die sich beim Jus nachweisen lassen, auch mit Bezug auf Theod. sich geltend gemacht haben werden. So das Motiv, in das Gesetzbuch lediglich aufzunehmen, was vom Standpunkte der Gesamtkodifikation nicht veraltet war: für schätzbares Material von lediglich historischer Bedeutung war in dem westgotischen Produkt, das sich die Aufgabe stellte, ein Gesetzbuch, nicht bloße Gesetzsammlung zu sein, kein Raum. ${ }^{1}$ ) Veraltet war dann insbesondere, was die ins Breviar rezipierte posttheodosianische Novellengesetzgebung ïberholt hatte. So werden, weil in der Materie nicht Theod., sondern der Novellenauszug, eine Novelle Valentinians III. (35 [Br. 12] \& 4), das letzte und vom westgotischen Gesetzgeber aufgegriffene Wort gesprochen hat, die auf den Handelsbetrieb von Personen geistlichen Standes bezüglichen Gesetze ([Tit.] 2, [const.] 8. 10.14 pr. $\$ 1.15 \$ 1.36$ pr.) ausgeschieden sein: diese nämlich regeln ihn des Näheren, während Valentinian ein entschiedenes Verbot ausspricht; es heißt in der Interpretation zur Novelle: ut negotiationes nullatenus exercere praesumant. Und Konstitutionen (2, 20.22. 27 pr. 28), die den zugunsten von Personen geistlichen Standes getroffenen gratuiten, insbesondere letztwilligen Verfügungen von Frauen, übrigens unter nicht ganz übereinstimmenden Voraussetzungen und mit verschiedenen Folgen entgegentreten, werden wegen einer in das Gesetzbuch übergegangenen Novelle Marcians (5 [Br. 5]), die ihnen ausdrücklich derogiert ( $\$ 2 \ldots$ ex prioribus constitutionibus .. quas ... praecipio abrogari), gestrichen $\operatorname{sein}^{2}$ ), ebenso die Gresetze, die sich auf die Fernhaltung der im Dienste städtischer Korporationen, insbesondere

die Sentenzen (vgl. 'Der Westgoth. Paulus', 1907, S. 11 [vgl. auch S. 18 11]) als auch hinsichtlich Gajus (vgl. 'Die Entstehung d. Westgoth. Gajus', 1905, S. 116f.), für alle nachweisbaren Streichungen der Vorlage eine Erklärung zu geben.

1) Dies liegt in dem Charakter des Unternehmens, ergibt sich aber auch aus den Worten des Einführungspatents (Exemplar auctoritatis [Commonitorium] bei Mommsen, p. XXXIII sq.). - - 2) Eine dieser Konstitutionen (27) enthält freilich auch Sätze, auf die sich die Novelle nicht bezieht (über das erforderliche Alter und die Verfügungsfähigkeit einer Diaconissa [pr.], sodann mit Bezug auf das Abschneiden der Haare der Frauen [\$ 1]). 
der Kurie, tätigen Personen, nebst Nachkommenschaft, aus dem Klerus beziehen (2, 3. 6. 19. 21), weil im Breviar auf diesen Gegenstand die posttheodosianischen Reformen Valentinians III. (Nov. 35 [Br. 12] § 3 und 5) und Majorians (Nov. 1 [Br. 1] \& 7) Anwendung finden. ${ }^{1}$ ) Veraltet konnte übrigens schon ein Gesetz im Rahmen von Theod. selbst sein, da das Gesetzbuch, indem es sich die Aufgabe stellte, ohne Rücksicht auf ihre praktische Verwendbarkeit, alle seit Konstantin erlassenen Leges generales zu sammeln, somit auch die außer Kraft getretenen, nicht eigentlich ein Gesetzbuch, sondern eine Gesetzsammlung gewesen ist: ${ }^{2}$ ) so besteht z. B. die Befreiung der Kirchen von der Unterhaltung der Wege und Brücken, die in einem Gesetze des Honorius vom Jahre $412(2,40)$ statuiert ist, schon zur Zeit der Publikation von Theod. nicht mehr, da eine jüngere Konstitution des 15. Buchs $(3,6)$, vom Jahre 423, das Gegenteil verordnete, ebenso wie die in älteren Gesetzen $(2,10 \mathrm{u}$. $14 \$ 4$; ferner 11, 1, 1) sanktionierte Immunität der katholischen Kirchen und Kleriker nebst Angehörigen von der Grundsteuer durch spätere Gesetze (2, 15. 33. 40; ferner $11,1,33)$ hinfällig geworden ist: $\left.{ }^{3}\right)$ gerade im 16 . Buche ist es sogar nicht selten, daß eine Konstitution die vorangehende ausdrücklich oder, falls sie ein $Z$ wischengesetz ist, durch Reaktivierung des durch letztere aufgehobenen Rechts abschafft. ${ }^{4}$ ) Aber wie im Jus hat nicht bloß Veraltetes den Platz räumen müssen: wenn ausgeschiedene Konstitutionen einen Rechtsinhalt besitzen, der sich im wesentlichen mit dem Rechtsinhalt von Texten deckt, die in das Gesetzbuch aufgenommen sind, wird sich die Streichung gewiß auf das Motiv einer Vermeidung von Wiederholungen gründen: z. B. konnten nach Aufnahme eines die Kleriker unzweideutig von

1) Es enthalten freilich die genannten Konstitutionen (2, 3. 6), aber auch sonstige im Breviar fehlende Texte (2, 11. 17. 33), die die Aufnahme in den Klerus betreffen, Materien, die jene Novellen nicht regeln (Unstatthaftigkeit willkürlicher und über,das Maß hinausgehender Ordination, der Ordination 'vulgari 'consensu' und aus Anlaß einer 'petitio', Verbot der Aufnahme wohlhabender Personen). - ${ }^{2}$ ) Vgl. Krüger, Geschichte d. Quellen u. d. Litter. d. röm. Rechts S. 287. 3) Vgl. God ofredus (vgl. S. 68) VI, 19. 21. 39. 89 u. V, 6. 7. 46. 389. -

4) Beispiele bei Krüger (vgl. N. 2), S. 287, u. Momm sen, p. CXIX. 
allen Lasten, 'munera', entbindenden Gesetzes - 'ab omnibus omnino muneribus excusentur' $(2,2$ [Br. 1, 1]) - weitere den gleichen Inhalt wiedergebende oder spezialisierende Konstitutionen (2, 1, 7-11. 14-16. 24. 29. 30. 34. 36. 38 . 40. 46.), wie sie sich in dem Vollständigkeit anstrebenden Theod. zahlreich finden, entbehrt werden und erhielten gewib darum im Gesetzbuche keine Stätte. Es ist aber auch selbstverständlich, daß Konstitutionen, die ausschließlich auf Verhältnisse des alten Rom oder des neuen Rom und seiner Sphäre oder Alexandriens Bezug haben, im Auszuge fehlen: ${ }^{1}$ ) mit dem Hinfall der Zugehörigkeit zum Imperium Romanum war im westgotischen Reiche ihre Anwendung hinfällig geworden. Wie ja im allgemeinen das Ausscheiden von Lebensverhältnissen, die durch ein Gesetz geregelt sind, seine Aufnahme in eine Kodifikation verbietet.

2. $\mathrm{DaB}$ die vorstehend geschilderten Motive obgewaltet haben, muß für um so sicherer gelten, als sie auch, wie erwähnt worden ist (vgl. S. 69), bei der Verkürzung der in das Gesetzbuch aufgenommenen Produkte des Jus, und zwar im besonderen der Paulinischen Sentenzen, eine Rolle spielten. ${ }^{2}$ ) Schon bei Veranstaltung der Auszüge aus dem Jus hat dann aber der Gesetzgeber auch dem Umstande Rechnung tragen müssen, daß die Autoren, Gajus Paulus, die ja vor Eintritt des - sozusagen - christlichen Zeitalters lebten, in ihren Schriften Äußerungen einschlossen, die sich zur Wiedergabe in dem Gesetzgebungswerk eines christlichen Kodifikators, wie es der Gotenkönig war, nicht eigneten. ${ }^{3}$ ) Bei dem ganz überwiegenden Inhalt der Juristenschriften konnte sich indessen dieser Sachverhalt nur recht selten zutragen: hingegen darf man von vornherein vermuten, daß gerade mit Bezug

1) Es gilt dies von einer Reihe von Texten (z. B. 2, 13. 37. 42. 43. 45, aus anderen Titeln z. B. 4, 5). $\left.-{ }^{2}\right)$ Der Nachweis ist geführt in den S. $68^{1}$ (S. 69) angeführten Schriften (Der westgoth. Paulus S. 11f. 30 f. u. Die Entstehung d. westgoth. Gajus S. $117 \mathrm{f} .120 \mathrm{f} .124 \mathrm{f}$ ). - - 3) Es ist anzunehmen, daß der Kodifikator die Anpassung der Sentenzen an christliche Verbältnisse zunächst mittels Ausscheidung von Texten, die Heiduisches betrafen, vollzogen haben wird. Nachweisen läßt es sich freilich nicht, da uns solche Texte der Sentenzen, welche Schrift wir überwiegend ja nur aus dem Auszuge kennen, nicht erhalten sind. Nachweisbar ist dagegen die Adaptation von Texten dieser Art an den christlichen Standpunkt mittels der Interpretation (vgl. Der westgoth. Paulus S. 18f.). 
auf das Religion und Kirche behandelnde Buch von Theod. die Verschiedenheit, die hinsichtlich ihrer zur Zeit der Kodifikation Theodosius' II. einerseits, zur Zeit der Verkündigung der Lex Romana im Westgotenreiche andererseits bestand, zur Ablehnung zahlreicher Gesetze durch den Kodifikator geführt haben wird: genauer ist, statt vom kirchenrechtlichen Status zur Zeit der Kodifikation von Theod., von dem bezüglichen Sachverhalt, wie er zur Zeit der Publikation der einzelnen Konstitutionen bestand, zu sprechen. ${ }^{1}$ ) Vor allem mußte der Umstand ins Gewicht fallen, daB Theodosius II. und die ganz überwiegende Zahl seiner im Gesetzbuche vertretenen Vorgänger auf dem Kaiserthron dem katholischen Glauben huldigten und, im Geiste der Zeitrichtung, auch von entsprechenden gesetzgeberischen Tendenzen erfüllt waren, während Alarich II. wie seine christlichen Vorgänger und seine näheren Nachfolger in der Herrschaft den Arianismus bekannten. Freilich ist es njcht wahrscheinlich, daß Alarich in seiner Lex Romana arianischen Tendenzen einen weiten Spielraum gelassen haben wird. Sein Gesetzbuch war für die römische Bevölkerung bestimmt, die doch gewiß ganz überwiegend nicht arianisch, sondern katholisch war - die Arianer nannten geradezu die Katholiken die 'Römer'2) -und Theod. XVI insbesondere sollte der Religion der Römer, der römischen Religion, Romana religio, und der römischen Kirche, Romana ecclesia, das ist der katholischen Religion und katholischen Kirche dienen ${ }^{3}$ ), doch wohl ohne Rücksicht darauf, ob die beteiligten Personen im einzelnen Fall Römer waren oder nicht; es ist z. B. kaum denkbar, daß das Vorrecht der Befreiung des Klerus von den munera, wie es Theod. XVI (vgl. z. B. 2, 2) und demgemäß das Breviar $(1,1)$ statuieren, Geistlichen der katholischen Kirche, die vom westgotischen Stamme waren, versagt gewesen ist. Die Bestimmung des Brevierauszugs von Theod. XVI für die katholische Kirche

1) Es läßt sich eben, im Hinblick auf seinen oben geschilderten Charakter, nicht eigentlich von einen Status von Theod. reden. 2) Gregor v. Tours, Liber in gloria Martyr. 24: Romanos enim vocitant nostrae homines religionis. - ${ }^{3}$ ) Der Ausdruck 'Romana religio' z. B. in Iohannis Abb. Monast. Biclar. Chron. ad a. 580 (MG. Auct. antt. XI, 216). Für 'Romana ecclesia' bedarf es nicht der Aufführung von Belegen. 
wird in den Theod. XVI entlehnten Konstitutionen selbst nicht ausgesprochen: doch ist sie darum nicht weniger sicher, ja gibt der Gesetzgeber ihr an anderer Stelle auch Ausdruck, indem er einen Novellentext (Theod. 3 [Br. 3] \& 5) aufnimmt bez. in der beigefügten Interpretation erläutert, wonach die von Juden - Iudaei omnes, qui Romani esse noscuntur ${ }^{1}$ ) dem Verbote zuwider errichteten Synagogen der katholischen Kirche zugewiesen werden. ${ }^{2}$ ) Es galt somit für den Gesetzgeber, die ganz überwiegend katholisch gerichtete Vorlage für die Regelung der Verhältnisse des Katholizismus im westgotischen Reiche auszuziehen, eine Aufgabe, die, so könnte es zunächst scheinen, zu arianischer Betätigung nur wenig Gelegenheit bot. Es kommt aber hinzu, daß die Politik dieses Westgotenkönigs durchaus nicht dazu neigte, durch Propagierung seines Glaubens den allezeit für die gotische Herrschaft bedenklichen, ja bedrohlichen, seit Eintritt der Franken in das katholische System aber geradezu verhängnisvollen Gegensatz von Arianismus und Katholizismus im Reiche zu verschärfen. ${ }^{3}$ ) Allem Vermuten nach wird auch die Gesetzgebungskommission für die Lex Romana aus Römern, das sind Katholiken, bestanden haben, wie auch $\mathrm{zu}$ den Sacerdotes bzw. Venerabiles episcopi, die nach dem Einführungspatent neben den Edlen (nobiles viri, electi provinciales) das von den Juristen (prudentes) vorgelegte Gesetzgebungswerk gutgeheißen haben, gewiß vorzugsweise katholische Bischöfe gehört haben werden. Aber dennoch darf man für ganz sicher halten, daB sich der Arianismus des Königs und seiner Goten in der Ausscheidung von Gesetzen, die von katholischen Tendenzen eingegeben waren, geltend gemacht haben wird. ${ }^{4}$ ) So wird aus diesem Grunde insbesondere der erste Titel fehlen, da er im Sinne des Kodifikators schon mit seiner Rubrik 'De fide catholica' ein

1) Es sind dies Worte der Interpretation des Breviars zu einem Texte von Theod. $(2,1,10)$. - $\left.{ }^{2}\right)$ Es heißt: ut quisque . synagogam extruxerit, conpendio ecclesiae catholicae noverit se laborasse. Die Interpretation sagt: nullam demuo audeant construere synagogam (sc. Iudaei). Nam si fecerint, noverint hanc fabricam ecclesiae catholicae profuturam. - ${ }^{3}$ ) Vgl. Aschbach, Geschichte d. Westgothen S. 166f:; Gams, Kirchengeschichte v. Spanien II, 1, 485 u. 486; Dahn, Urgeschichte d. germ. u. roman. Völker I, 366f. - ${ }^{4}$ ) Übereinstimmenc 
Programm enthält oder, mit anderen Worten, das katholische als das wahre christliche Glaubensbekenntnis hinstellt, dann aber auch die bekannten Konstitutionen Theodosius' des Großen vom Jahre 380 und 381 (2 u. 3) - die Aufnahme der ersten und der letzten Konstitution des Titels verbot sich aus andern Gründen (vgl. S. $75^{1}$ u. $84^{1}$ ) - einschließt, die die Annahme des katholischen Glaubens (Christianorum catholicorum nomen) den Völkern des Reiches geradezu befehlen und die Ausantwortung aller Kirchen an die katholischen Bischöfe vorschreiben: Proklamierung der Fides catholica enthalten aber auch andere Gesetze, wie eine die Formel des Nicaenum einschließende $(5,6)$ und selbst die beiden letzten Konstitutionen von Theod., die neben einem vom geistlichen Forum handelnden und in das Breviar $(5,1)$ aufgenommenen Gesetze den letzten Titel (11), 'De religione', bilden. Es war für den arianischen Gesetzgeber geradezu ein Gebot der religiösen Selbsterhaltung, diesen Satzungen den Zutritt zu seiner Kodifikation abzuschneiden: mit ihrer Aufnahme hätte er ja doch die eigene und seiner Goten religiöse Existenz aufs Spiel gesetzt. Womöglich noch einleuchtender ist, daß in dem Gesetzbuche Alarichs keine Stätte sein konnte für Konstitutionen, die den Arianismus ausdrücklich als Ketzerei bezeichnen und behandeln ${ }^{1}$ ): es sind Texte des Titels De haereticis $(5)^{2}$ ), die der Schreibweise der Zeit entsprechend überdies weithin so heftig und schmähend gegen die Arianer ausfahren, daß Alarich mit ihrer Aufnahme sich und seinem Volke gleichsam einen Schlag in das Gesicht versetzt und ein Gesetzgeber von modernem Ehrgefühl überhaupt leicht von der Verwertung einer Quelle, die solche Beschimpfungen einschloß, abgesehen hätte. ${ }^{3}$ ) Dem arianischen Gesetzgeber

Hänel, p.XVI. Es heißt bei ihm: denique libri XVI, etsi ad religionem christianam spectant, non tot constitutiones, quot poterant exspectari, selecti sunt. Nam Visigothi Ariani erant, Codicis Theodosiani compositores catholicae fidei sectatores, illis igitur multae Romanorum imperatorum leges videntur displicuisse.

1) Mit Grund bemerkt $\mathrm{Ha}$ enel, im Anschluß an die vorstehend aufgenommenen Sätze: quare nou mirum est, deesse titulum de Fide catholica et quintum de Haereticis, in quo Ariani repetitis legibus condemnati erant. - ${ }^{2}$ ) Sie sind aufgeführt bei Godofredus im Paratition ad h.t. (VI, 116). - ${ }^{3}$ ) Ich führe einiges der Art an: Arriani sacrilegii 
konnte es aber auch nicht behagen, seinem Gesetzbuche Satzungen einzuverleiben, die der katholischen Kirche und seinem Klerus eine bevorrechtete Stellung einräumen: z. B. ein Kult und Gotteshaus der Ecclesia catholica gegen sakrilegischen Einbruch schützendes Gesetz $(2,31)$ oder eine Verordnung, die lediglich der katholischen Kirche - sanctissimum catholicae venerabileque concilium - Erbeinsetzungsfähigkeit zuschreibt $(2,4)$, oder Konstitutionen, die ausschließlich ihren Bischöfen und ihrem Klerus - ecclesiae catbolicae clerici und antistites, catholicae religionis clerici - Freiheit von den munera gewährten $(2,1.11 .36 ; 5,1)$. Sie waren im Westgotenreiche nicht allein von dem Standpunkte aus anstößig, daß der Arianer für seinen Glauben zum mindesten Gleichberechtigung in Anspruch nahm: daß der Konfession des Königs und der Kriegerkaste, im Verhältnis zu der katholischen, eine untergeordnete Stellung beschieden sein sollte, war auch aus politischem Gesichtspunkt unerträglich. Aus diesem Grunde wird man es aber selbst haben vermeiden wollen, ein Gesetz in die Kodifikation aufzunehmen das den Arianern neben den Katholiken eine Art geduldeter Existenz einräumt. ${ }^{1}$ ) Nach alledem begreift sich wohl, daß von den zahlreichen Konstitutionen des sechzehnten Buchs, in denen der katholischen Religion und Kirche, des katholischen Glaubens ausdrücklich, sei es mit dieser, sei es mit einer andern unzweideutigen Bezeichnung gedacht ist, im Breviar keine einzige wiederkehrt, aber auch die nicht ganz spärlichen derartigen Texte aus andern Büchern von Theod. fehlen. ${ }^{2}$ ) Daß im Breviar unter den kirchenrechtlichen Texten,

venenum $(6 \S 1)$; Vitiorum institutio deo atque hominibus exosa, Eunomiana scilicet, Arriana .. (12); Eunomiani, Macedoniani, Arriani .. pro suis erroribus famosa sunt nomina (13); De haereticis omnibus, quorum et errorem execramur et nomen, hoc est de Eunomianis Arrianis (60).

2) Aus diesem Gesichtspunkt läßt sich z. B. das Fehlen einer Konstitution vom Jahre 386 (4,1) erklären, die den Gottesdienst Andersdenkender gegen die Eingriffe derjenigen schützt, die sich allein das Recht der Vereinigung zuschreiben: gemeint sind mit den letzteren die Katholiken, mit den ersteren die Arianer. Auch eine zweite Konstitution dieses Jahres $(1,4)$ kann man anführen, wozu Godofredus die folgende Summe gibt: Valentiniani Iun. Constitutio quae Arianis nou minus quam Catbolicis coeundi potestatem tribuit. - 2) Bezüg- 
die sich ja nicht lediglich in Theod. finden ${ }^{1}$ ), einmal und zwar in dem Novellenauszug die katholische Kirche genannt ist, wurde bereits hervorgehoben (vgl. S. 73): diese Erwähnung konnte aber der arianische Gesetzgeber unbedenklich passieren lassen. ${ }^{2}$ ) In welcher Form der letztere im übrigen sich bei der Redaktion des Gesetzbuchs, zumal gegenüber den katholischen Redaktoren und den katholischen Bischöfen, zur Geltung gebracht hat, kann dahingestellt bleiben.

3. Es läßt sich das Motiv der Ausscheidung, wovon vorstehend (2) die Rede war, auch in den letzterwähnten Fällen unter den Gesichtspunkt bringen, daß die Konstitutionen, die gestrichen wurden, das Lebensprinzip des von dem westgotischen Gesetzgeber und seinem Stamme gehuldigten Arianismus verneinten. Es fragt sich aber, ob sich nicht weitere Ausscheidungen von Konstitutionen damit werden erklären lassen, daß ihr Inhalt wenn auch nicht dem Lebensprinzip, immerhin einer dem Arianismus innewohnenden Tendenz widerstrebte. Diese Frage gestattet eine sichere Beantwortung nur in dem Falle, daß uns solche Tendenzen von anders her bekannt sind: es ist indessen, soweit ich sehe, der Forschung bisher nur in wenigen Punkten geglückt, in dieser Hinsicht sichere Ergebnisse zu erzielen, und ich unterlasse selbst einen Versuch, weiter zu kommen, so dab ich mich mehrfach mit nicht viel mehr als der bloßen Fragestellung begnüge, ob nicht Streichungen von Gesetzen auf einem bisher nicht ermittelten arianischen Grundsatze beruhen. Am ehesten möchte man erwarten, in dem Fallenlassen ganzer

liche Texte von Theod. XVI und der anderen Bücher finden sich aufgeführt bei Godofredus (VI, 2 u. 3).

1) Eine Zusammenstellung der kirchenrechtlichen Texte des Breviars findet sich in der Schrift 'Breviarium Alaric., Röm. Recht i. fränk. Reich’ (1903) S. 781 f. - ${ }^{2}$ ) Es heißt dann noch zum Schluß (\$10) der Novelle Theodosius' II (3 [Br. 3]) von dem Adressaten der Konstitution: cui cordi est cum divinis tum principalibus adhibere iussionibus famulatum, quae insatiabili catholicae religionis honore decrevimus. Ein für das Empfinden des Arianers wohl ein wenig anstößiger Text, der indessen mitgenommen werden mußte, da die für brauchbar befundenen Stücke der Vorlage unverkürzt aufgenommen wurden (vgl. S. $84^{3}$ [85]): praktisch ist natürlich die Bemerkung ganz harmlos und hat daher auch in der Interpretation keine Spur zurückgelassen. 
Titel, soweit es bisher nicht erklärt ist (vgl.S. 73), zumal einzelne recht umfangreich sind, einem solchen zu begegnen. So insbesondere in der Streichung des 'De haereticis' rubrizierten Titels (5), mit dem nicht weniger als 66 Gesetze der Vorlage ausgefallen sind. Weithin wird sich hier indessen die Ausscheidung damit erklären, daß zur Zeit der Abfassung des Breviars die Häresien, von denen die Konstitutionen handeln, wenigstens im Umkreise der Herrschaft des Gesetzbuchs nicht vorkommen. ${ }^{1}$ ) Der Ausfall weiterer Gesetze, die das katholische Glaubensbekenntnis proklamieren (vgl. S. 74), die Arianer ächten (vgl. S. 74) und den Katholizismus privilegieren (vgl. S. 75), hat sich uns bereits als einfache Befolgung eines Gebots der religiösen Selbsterhaltung ergeben. Indessen aus keinem anderen Grunde widerstrebten der Aufnahme in die Kodifikation auch alle diejenigen Konstitutionen, die sich ohne Hinweisung auf den Arianismus, andererseits aber auch ohne Beschränkung auf eine bestimmte Sekte gegen die Häretiker wandten. Häretiker ist ja doch ein jeder, der, sei es auch in einem unbedeutenden Punkte, von der Lehre des Katholizismus abweicht, oder mit anderen Worten, Häretiker ist nicht der andersgläubige Christ überhaupt, sondern der Christ, der nicht orthodoxgläubig ist, so daß auch der Arianer darunter fällt: dies ist der Sprachgebrauch von

1) Einen Katalog der in Theod. und insbesondere im fünften Titel vorkommenden Häresien liefert Godofredus (VI, 116 sq.). Meistenteils gehören sie ausschließlich dem Orient an. So finden sich denn in unserem Titel, aus dem fünften Jahrhundert, auch nur wenige Konstitutionen aus dem Westreich und betreffen die Donatisten (37. 41. 43. 44. 46. 52. 54. 55), Priscillianisten (40. 43) und insbesondere die Manichäer; eine Konstitution (5:3) ist gegen Jovinian und seinen Anhang gerichtet (vgl. S. 107 f.). Was dann im besonderen das Verhältnis von Theod. zu Häresien - abgerechnet den Arianismus - betrifft, die auf westgotischem Bodev nachweisbar sind, so kann für die gallischen Regionen des tolosanischen Reiches, die vor dem Jahre 507 einen großen Tei] ausmachten, auf ein Wort des God of redus (VI, 117 in fine [vgl. auch p.48]) hingewiesen werden : illud memorabile, per Gallias nullam haeresin hoc Codice memorari. Diese Bemerkung ist wohl dahin zu verstehen, daß Theod. XVI kein nach Gallien gerichtetes Ketzergesetz bzw. keine von häretischen Bestrebungen auf dem Boden Galliens bandelnde Konstitution enthält. Dasselbe wird man wohl mit Bezug auf das tolosanische Reich überhaupt sagen können. 
Theod., nicht allein nach einer Definition des Wortes in einer Konstitution des Arcadius $\left.(5,28)^{1}\right)$, sondern überall und auch da, wo die Fides catholica nicht ausdrücklich als das Gegenstück der Häresie bezeichnet ist. Ganz gewiß war dies aber auch der Sinn, den gerade diejenigen, die das Gesetzbuch zunächst anging, das ist die römische bzw. katholische Bevölkerung des westgotischen Reiches, mit dem Worte verband. Wenn nun aber auf diesem Boden der Arianismus die dominierende - dominierend in doppelter Bedeutung Häresie gewesen ist, mußte auch dieses Wort überwiegend geradezu mit ersterem identisch gelten, wie denn bei den katholischen Schriftstellern, die als Zeitgenossen die Periode des katholisch-arianischen Dualismus im westgotischen Reiche behandeln, z. B. bei Gregor von Tours und bei Isidor, der Arianer der Häretiker, der Arianismus die Häresie ist. ${ }^{2}$ ) Der Umstand, daß der Gesetzgeber die gegen Häretiker schlechthin gerichteten Verfügungen der Vorlage in seiner Kodifikation nicht dulden konnte, brauchte ihn dagegen nicht zu hindern, Satzungen gegen eine bestimmte Häresie aufzunehmen, an deren Verfolgung auch vom Standpunkte des Arianers kein Anstoß genommen werden konnte. Er hat dies auch getan, indem er im Punkte der Reaktion gegen die Manichäer die Erbschaft des katholischen Kaisertums übernahm. Es geschah indessen nicht im Wege der Aufnahme von Konstitutionen aus der großen Zahl darauf bezüglicher Texte von Theod. ${ }^{3}$, sondern durch Einreihung der mit 'De Manichaeis' rubrizierten Novelle Valentinians III. $\left(18[\right.$ Br. 2] $\left.) .{ }^{4}\right)$ Sie, gegen die sich das Gesetz, wie man an-

1) Es heißt: haereticorum vocabulo continentur .., qui vel levi argumento iudicio catholicae religionis et tramite detecti fuerint deviare. - ${ }^{3}$ Z. B. in den Schriften Gregors (In gloria martyr., Rubr. 80, und Hist. Franc., 2, 3 Rubr. u. Text), ferner in der Hist. Goth. Isidors, wenn er König Theudis schlechthin als Häretiker bezeichnet (MG. Auct. antt. XI, 283). - ${ }^{3}$ ) Sie sind aufgeführt bei Go do fred u s, (VI, 117). - 4) Ingleichen bezieht sich auf sie ein Passus in der bereits genaunten (vgl. S. 73) Novelle Theodosius' II (3 [Br. 3] § 1.9), die die Rubrik' De Iudaeis Samaritanis haereticis et paganis' führt. Es wird hier (\$9) eine Anzahl von Häresien aufgezählt (Interpr. 'De reliquo vero haec lex damnat sectas, quae nominatin in hac lege continentur insertae') und bemerkt, daß die ihrethalben erlassenen Gesetze unverzüglich ausgeführt werden 
nehmen darf, ohne Unterschied des Stammes, dem sie angehören, wendet - der Häretiker kommt nicht als verbrecherischer Römer in Betracht, sondern seine Verfolgung wird als Angelegenheit der Ecclesia Romana angesehen - mögen die einzigen Häretiker sein ${ }^{1}$ ), gegen die der westgotische Gesetzgeber, begreiflicherweise dabei die im Munde des Arianers AnstoB erweckende Bezeichnung des Häretikers vermeidend ${ }^{2}$ ), eingeschritten sein wird. ${ }^{3}$ ) Dem Eindringen

sollen. Unter den Häretikern werden, uud zwar zuerst, die Manichäer genannt. Nur auf die Manichäer aber kann im Rahmen der Kodifikation der Text direkt bezogen werden ( $v g l$. die folg. Note), da diese in Sachen der Häresie eben kein anderes als das gegen die Manichäer gerichtete Gesetz Valentinians III. enthält.

1) In der Aufzählung von Häresien der Novelle Theodosius' II. (vgl. vor. Note) werden auch die Priscillianisten genannt, die ja auch um die Zeit der Publikation des Breviars in westgotischen Reiche vorgekommen sein werden: denn der Priscillianismus ist, wie die spanische und südgallische überhaupt, die in Resten auch noch in den Zeitläuften westgotischer Herrschaft nachweisbare Häresie (vgl. Menendez Pelayo, Historia heterodoxos españoles I, 100sq. 170.171). Man könnte meinen, daß der Gesetzgeber, indem er Ausführung der gegen Manichäer und Priscillianisten erlassenen Gesetze verordnet, die Novelle Valentinians III., die sich ausschließlich gegen erstere wendet, analog gegen letztere augewendet wissen will. Wahrscheinlicher ist mir, daß in Sinne des Gesetzgebers unter den Manichäern auch die Priscillianisten verstanden werden, da Priscillian wegen Manichäismus verurteilt wurde und der spanische und gallische Priscillianismus mit dem Manichäismus in unverkennbaren Zusammenhang stand (vgl. Real-Enzykl. für prot. 'Theol. ${ }^{3}$ XVI, 64 u. 65 und XII, £26 u. Arnold, Cäsarius v. Arles S. 157). $\left.{ }^{2}\right)$ Das Wort kommt im Breviar, außer im 'Text der Novelle Theodosius II. (Rubrik und soust [\$1 haereticorum genera; $\$ 9$ haereticae fatuitatis auctores]), nicht vor. Die Interpretation zur Novelle spricht nicht von Häresien, sondern von Sekten (vgl. S. $\left.80^{1}\right) .-{ }^{3}$ ) Die Chronik des Hydatius ad a. 448 (MG. Auct. antt. XI, 25) berichtet von dem Auftreten eines Römers Pascentius im Westen der spanischen Halbinsel um die Mitte des 5. Jahrhunderts, der dem Manichäismus huldigte und Proselyten machte. Menendez Pelayo (vgl. N. 1), S. 170, nimmt an, daß Pascentius zu den aus Rom flüchtigen Sektirern gehörte, gegen die sich die Dekretale Leos vom Jahre 444 (Jaffé, Regesta ${ }^{2}$ n. 405) richtet. Cäsarius von Arles eifert als Bischof (seit 502) gegen ron ibm als manichäisch bezeichnete Anschaungen, die auch die Aufnahme antimanichäischer Kapitel in gallischen Kanonensammlungen der Mitte des 6. Jahrhunderts veranlaßt haben werden: vgl. Arnold, a. a. O. S. 156. 157. 362 . 
neuer ketzerischer Sekten war durch einen Text der Sentenzen des Paulus, natürlich gegen den Sinn ihres Autors, der lediglich Erscheinungen des Heidentums im Auge hatte, ein Riegel vorgeschoben. ${ }^{1}$ )

4. Ich glaube wohl, daß sich mit den aufgeführten Momenten die Ausscheidung aller den Titel De haereticis bildenden Konstitutionen erklärt, danach aber kein Grund zu der Annahme vorliegt, daß dabei ein besonderes arianisches Prinzip zur Geltung gekommen ist. Eher noch könnte man annehmen, daß es beim Ausfall des Titels De monachis (3) der Fall ist ${ }^{2}$ ), wenn es zutreffen würde ${ }^{3}$ ), daß der Arianismus den Standpunkt völliger Abweisung der mönchischen Virginität einnahm. ${ }^{4}$ Für sicherer aber darf es gelten, daß der Streichung des vierten Titels, mit der charakteristischen Überschrift ${ }^{\mathrm{C}} \mathrm{De}$ his qui super religione contendunt', und insbesondere des sechsten mit der Rubrik 'Ne sanctum baptisma iteretur',

1) Es ist dies die folgende Stelle $(5,23,2)$ : qui novas et usu vel ratione incognitas religiones inducunt, ex quibus animi hominum moveantur, honestiores deportantur, humiliores capite puniuntur. Cod. Paris. 4403, Saec. VIII/IX, den Krüger in seiner Ausgabe der Sentenzen (Coll. libr. iur. anteiust. II) als Repräsentant eines der beiden Handschriftentypen des Breviarauszugs verwertet hat, liest statt 'et usu' vielmehr 'sectas' und fügt vor 'deportantur' ein 'exilio' ein: ich halte beide Lesarten, insbesondere aber das Wort 'sectas', das Krüger in den Text (5, 21, 2 [p. 127]) anfnimmt, für Interpolation einer, wie sich zeigen wird (vgl. S. $93 \mathrm{f}$.), ihre eignen Wege gehenden Überlieferung, übrigens für eine Interpolation, bei der die dem Texte vom Kodifikator zugeschriebene Beziehung auf die Häresie sichtbarer wird, als in der Fassung des Paulus: das Wort 'Secta' im Sinne einer christlichen Religionsgenossenschaft, übrigens auch der katholischen, ist in der christlichen Kaiserzeit ganz üblich (vgl. z. B. 5, 7 § 3. 15. 44.66 pr. u. die S. $78^{3}$ a. Interpretation). - $\left.{ }^{2}\right) \mathrm{Zwingend}$ ist indessen diese Annahme selbst unter der angegebeuen Voraussetzung nicht, da von den beiden Konstitutionen, aus denen der Titel besteht, die zweite die erste, mit ihrer Verweisung der Mönche nach 'deserta loca et vastas solitudines', aufhebt und kein Grund vorhanden ist, der gewährten Freizügigkeit ('liberos in oppidis largimur eis ingressus') ausdrücklich zu gedenken. - ${ }^{3}$ ) $\mathrm{Zu}$ dieser Annahme neigt $\mathrm{H}$. v. Schubert, Das älteste germ. Christentum oder der sog. "Arianismus" der Germanen S. 19. 4) Es fehlen aus Theod. im Breviar auch die sonstigen von Godofredus im Paratitlon ad h. t. (VI, 106 u. 107) aufgeführten Konstitutionen von Theod. XVI und der weiteren Bücher. Eine Ausnahme bildet die eine Konstitution in dem Titel 'De clericorum et monachorum' $(5,3)$. 
die außerhalb dieses Titels in Theod. XVI aufgenommenen gegen die Wiedertaufe gerichteten Gesetze inbegriffen ${ }^{1}$ ), eine und zwar besonders bedeutungsvolle Tendenz des Arianismus zugrunde liegt, die Tendenz nämlich, den Katholizismus durch Gewinnung seiner Anhänger zu überwinden. ${ }^{2}$ ) Hierauf hätte Alarich durch Aufnahme der genannten Gesetze geradezu Verzicht geleistet, was bei aller freiwilligen und unfreiwilligen Beschränkung ihm doch nicht zugemutet werden konnte: denn welches war unter den Entstehungsverhältnissen seines Gesetzbuchs das Mittel, um den Übertritt der Katholiken zu erzielen, und auf welchem Wege vollzog er sich? Auf keinem anderen Wege als durch den Sachverhalt, gegen den Rubrik und Inhalt des Titels 'Ne sanctum baptisma iteretur' ankämpft, die Wiedertaufe der konvertierenden Katholiken, und weithin durch kein anderes Mittel als dasjenige, das in dem Titel 'De his qui super religione contendunt' verpönt ist, die religiöse Debatte, das "Religionsgespräch." 3 ) Nicht der Zwang ist das von den Arianern, indessen auch von der andern Seite, geübte normale Mittel, um den Gegner zum Übertritt zu veranlassen, sondern die Einwirkung auf die Überzeugung, die Überredung, ja die Überwindung auf Grund einer Diskussion der religiösen Frage. ${ }^{4}$ ) Noch gegen Ende des Jahrhunderts (586) vollzog sich der entscheidende Übertritt Reccareds zum Katholizismus derart, daß der König vor einem aus arianischen und katholischen Bischöfen zusammengesetzten Konzil, nach vorgängigem Kolloquium der

1) Es sind insbesondere mehrere Texte des Titels De haereticis (5. 54. 58. 65; ferner 7, 4). - ${ }^{2}$ ) Anderer Ansicht ist D a h n , Die Könige der Germanen XI $203 f$., wenn er bemerkt, daß die arianische Kirche nie ,katholische Strebungen" zeigte und nur eine - nicht einmal ndie" Landeskirche sein wollte : er denkt dabei freilich zunächstan Burgund. - $\left.{ }^{3}\right)$ Schon A s c b b a c h, a. a. O. S. 220, gebraucht den Ausdruck "Religionsgespräch". - 4) Dies ist obne Zweifel der Eindruck, den wir aus den Mitteilungen der Berichterstatter empfangen, bei deren Würdigung überdies noch in Betracht kommt, daf sie, indem sie der katholischen Seite angehören, die Neigung besessen haben werden, den psychologischen Zwang in körperlichen umzusetzen und $\mathrm{da} \beta$ es in manchen Zeitläuften (Eurich, Leovigild) in der Tat auch anders, als in der im Texte charakterisierten Weise zugegangen sein wird (vgl. Dahn, a.d.S. $73^{3}$ a. O. I, 500 f.).

Zeitschrift für Rechtsgeschichte. XXXI. Kan. Abt. I. 
streitenden Bekenner, seine Konversion aussprach ${ }^{1}$ ), wie sich aber auch auf dem gallischen Boden des Reichs, unter fränkischer Herrschaft, die Praxis erhielt, gegen den Arianismus. jeden $Z$ wang zum Übertritt zu vermeiden. ${ }^{2}$ ) Religionsgespräche ${ }^{3}$ ) sind auch bezeugt. ${ }^{4}$ ) Was aber die Wiedertaufe anlangt, so wurde von den Arianern bez. den Westgoten, die auch von zahlreichen andern Sekten geforderte zweite Taufe, die die Kaisergesetze von Theod. XVI zu einem Irrtum, einer Missetat, einem Verbrechen siempelten ${ }^{5}$ ), nicht nur nicht perhorresziert, sondern geradezu zum Erfordernis des Übertritts eines Katholiken zum Arianismus erhoben. ${ }^{6}$ )

1) Es heißt in Johannis Abb. Monast. Biclar. Cbron. ad a. 587 (a. d. S. $72^{3}$ a. 0 . p. 218): Reccaredus primo regni sui anno mense $\mathrm{X}$ catholicus deo iuvante efficitur et sacerdotes sectae Arrianae sapienti colloquio aggressus ratione potius quam imperio converti ad catholicam fidem fecit. - 2) Vgl. E. Löning, Geschichte d. deutschen Kirchenrechts II, $48 \mathrm{f}$. In der Sache stimmt hiermit auch Dahn, Die Könige der Germanen V 3, 194 f., überein. - ${ }^{3}$ ) Es mag sein, daß der Gesetzgeber von Theod. auf das „öffentliche“ Religionsgespräch abzielt, wie ja auch das Gesetz Theodosius' I (2) in unserem Titel gegen das Auftreten in der Öffentlichkeit (Nulli egresso ad publicum .. patescat occasio) reagiert. Indessen die Rubrik des Theod. spricht, anders als die Wiederholung im Justinianischen Kodex $(1,1)$, die ein 'publice' einfügt, dieses Erfordernis nicht aus. Man sieht übrigens arianische Könige die Häupter der beiden Kirchen aufrufen, um öffentlich über ihre Konfessionen zu diskutieren (vgl. D a h n, Die Könige der Germanen XI, 219 f. u. v. S ch ubert, Die Anfänge des Christentums bei den Burgundern S. 26). - -) A s ch bach, a. 凡. O. S. $220^{96}$, weist hierfür anf eine Diskussion des Bischofs Basilius von Aix, wovon Sidonius A pollinaris $(5,6)$ berichtet. Man sehe ferner bei Gregor von Tours, Hist. Franc. 2, 3 u. 6, 40 und Liber in gloria Martyr. 80. Dahn, a.d. S. $73^{3}$ a. O. I 502, spricht von den Glaubensgesprächen, die Gregor von Tours wiederholt mit gotischen A rianern, zumal mit den nach Orleans oder Paris durchreisenden Gesandten hielt (vgl. anch Dahn, Die Könige der Germanen VI 374 v. 375). - ${ }^{5}$ ) Vgl. die bezüglichen Texte im Paratitlon zu dem Titel (6) bei Godofredus (VI, 213). - ${ }^{\text {B) Vgl. }}$ Aschbach, a. a. O. S. 205; Hefele, Konziliengesch. II 594f.; Dahn, a. d. S. $73^{3}$ a. O. I, 500. Stellen aus der Literatur sind z. B. Isidor, Hist. Goth. (MG. A uct. antt. XI, 287. 288) u. Gregor von Tours, Hist. Franc. 5,38 ( 2,2 von den Vandalen). Auch der sich gegen die Wiedertaufe bei den Häretikern wendende Kanon des Konzils v. Orleans v. J. 538 (MG. Concil. I 83) mag, neben den ausdrücklich hervorgehobenen Bonosianern, Arianer im Auge haben. In Johannis Abb. Monast. Biclar. Chron. ad a. 580 (a. d. S. $72^{3}$ a. O. p. 216) wird dem König Leovigild die 
Wenn endlich der von dem Heidentum handelnde Titel (10) fehlt, der ganz überwiegend Verbots- und Strafgesetze enthält ${ }^{1}$ ) und mit einer Konstitution Theodosius' II. (25) abschließrt, die die Ausübung des heidnischen Kults mit Todesstrafe bedroht und die Aufhebung der heidnischen Kultstätten verordnet, so darf man sich diesen Sachverhalt schwerlich aus der Annahme erklären, daß zur Zeit der Publikation des Breviars im Bereiche seiner Herrschaft der Paganismus ausgerottet war. Hiergegen spricht schon der Umstand, daß, wovon zu reden sein wird (vgl. S. 94, 109, 121), die doch aus verwandten Entstehungsverhältnissen, wie das Breviar, hervorgegangenen, der Zeit nach nur noch jüngeren sonstigen Auszüge von Theod. XVI unserem Titel Konstitutionen entlehnen, die gegen den Paganismus reagieren: es darf aber auch aus anderen Gründen als sicher angesehen werden, daß das Christentum noch nicht überall durchgedrungen war. ${ }^{2}$ ) Wird auf den Ausschluf des ganzen Titels ein arianisches Prinzip der Duldung eingewirkt haben? ${ }^{3}$ ) Duldung, nicht Anerkennung, so daß auch

Neuerung zugeschrieben, da $\beta$ bei der Konversion von der Wiedertaufe abgesehen und lediglich Handauflegung und Teilnahme an der Kommunion erfordert wird.

1) Außerdem Gesetze, die die ehedem dem heidnischen Dienste gewidmeten Kultstätten vor Zerstörung schützen (3. 8. 15. 18) und die ursprünglich mit heidnischem Ritus verknüpften festlichen Veranstaltungen erhalten wissen wollen (3. 17). Eine Konstitution (24) verbietet schließlich eine Behelligung von Heiden und Juden, die keinen äußeren Anstoß geben. - ${ }^{2}$ ) Ich verweise hierfür auf die auf das Frankenreich sich beziehenden Ausführungen von Löning, a. d. S. $82^{2}$ a. O. II $57 \mathrm{f}$, wonach noch im 6. (und 7.) Jahrhundert in Gallien vielfach Heiden saßen. Näheres findet man bei Dahn, a. d. S. $73^{3}$ a. O. III 160 . 366f. 546. 615. 658, u. Die Könige der Germanen VII 3, 199f., u. insbesondere 195. 197. 202. 203. 205. 213: es finden sich darunter auch Belege für das Vorkommen des Paganismus auf dem (ehedem) westgotischen Boden Galliens, die über das Jahr 500 hinausreichen. Speziell über Spuren von Heidentum während der ersten Hälfte des 6 . Jahrhunderts im westgotischen und burgundischen Gallien handeln eingehend Arnold, a d. S. $79^{1}$ a. O., S. 156. 157. 166.167. 179 u. Dahn, a. d. zuletzt a. O. XI 201 u. 228. - ${ }^{3}$ ) Es kommt freilich in Betracht, daß die in das Breviar aufgenommene Novelle Theodosius' II. (3 [Br. 3]), unter der Rubrik 'De Iudaeis Samaritanis haereticis et paganis' sich gegen die Heiden wendet $(\$ 1 \mathrm{u} .8)$ und $(\$ 8)$ die folgenden Worte enthält: decrevimus, ut, quicumque pollutis contaminatisque mentibus in sacrificio quolibet in loco fuerit compre- 
die freilich sehr spärlichen Gesetze von Theod,, die den Standpunkt einer Parität von Heidentum und Christentum vertreten ${ }^{1}$ ), ausgeschieden sind, und Duldung, mit der sich be= greiflicherweise eine Reaktion gegen Handlungen, in denen schon das Altertum eine verbrecherische Kultübung erblickte, wohl vertrug ${ }^{2}$ ), die aber auch eine Reaktion gegen die Apostasie zum Paganismus nicht verbot, zumal wenn sie sich, wie es der Breviarauszug tut, auf die eine Folge des Ausschlusses der Testierfähigkeit beschränkt ${ }^{3}$ ), hingegen die

hensus, in fortunas eius, in sanguinem ira nostra consurgat. Es ist aber bemerkenswert, da $\beta$ die Interpretation, die sich doch die Aufgabe stellt, den Geltung besitzenden Inhalt der Vorlage erklärend oder wenigstens registrierend anzugeben, dies zwar mit Bezug auf die Juden (und Samaritaner), auf die sich der Inhalt der Novelle vorzugsweise bezieht, tut, bezïglich des übrigen Inhalts (De reliquo) aber, unter Verweisung auf den Text der Vorlage, nur der Häretiker gedenkt (vgl. S. $78^{4}$ ), so daß von den Heiden mit keinem Worte die Rede ist. Auf diesen Umstand stützt auch E. Löning, a. a. O. II 57, die Anmahme, daß, im Sinne des westgotischen Gesetzgebers, die Vorschrift der Novelle keine Geltung besitzt. Hierfür spricht auch, daß, wie Löning bemerkt, die Epitomae des Breviars den Satz nicht wiedergeben, außer, worauf Dahn, Die Könige der Germanen V 3, 195 u. 196, hinweist, die Epitome Monachi. Dahn selbst meint übrigens, daß der westgotische Gesetzgeber auch die gegen die Heiden gerichtete Sanktion der Novelle gelten lassen will.

1) Das unserem Titel angehörige Gesetz Konstantins vom Jahre 320 (1), das die Verwertung der Haruspizin aufrechthält und regelt, gehört hierher. Indessen auch ein zweites dieses Kaisers v. J. 323 $(2,5)$, das die Christen vor dem Zwange der Zuziehung zu heidnischen Opfern schützt, und ein Gesetz v. J. 365, die erste Konstitution des ersten Titels, das gegen die Verwendung von Christen als Tempelwache einschreitet, geht von diesem Standpunkte aus. - 2) Die Texte des Breviars, von denen die Mehrzahl dem Sentenzenauszug (5, 23 u. 25), nur einzelne Theod. $(9,13)$ angehören, sind aufgeführt und wiedergegeben ${ }^{\circ}$ Breviarium Alaric.' (vgl. S. 76 ${ }^{1}$ ) S. 558-560.- ${ }^{3}$ ) Es heißt in einer Konstitution (3) des Titels 'De apostatis' (7): Christianorum ad aras et templa migrantium negata testandi licentia vindicamus admissum. Hernach ist von der Apostasie ins Judentum die Rede. Es folgt schließlich zudritt die Apostasie zum Manichäismus und, auf alle drei Fälle der Apostasie sich beziehend, der Satz, daß die Reaktion gegen die Testamente der Apostaten auf den Zeitraum von fünf Jahren nach ihrem Tode beschränkt ist. Das Gesetz ist, als einziges des Titels, auch in das Breviar $(2,1)$ übergegangen: indessen fehlt hier dieser dritte Abschnitt, worauf die Interpretation, die im übrigen den Inhalt für nicht erläuterungsbedürftig erklärt, mit den Worten hinweist, daß der von den 
weitere Folgen statuierenden Gesetze von Theod. ausscheidet. ${ }^{1}$ ) Auch in Titeln mit Konstitutionen, von denen eine Auswahl in das Breviar übergegangen ist, mag manche Streichung auf einen prinzipiellen Standpunkt zurückgehen. Man nehme den von den Juden handelnden Titel (8), dessen große Zahl von Gesetzen (29) im Breviar auf zwei zusammengeschrumpft ist. $\mathrm{Zu}$ einem guten Teil erklärt sich die bedeutende Reduktion allerdings aus dem Umstande, daß sich im Breviar an anderer Stelle Text aufgenommen findet, nämlich insbesondere eine die Rechtsstellung der Juden regelnde Novelle Theodosius' II. (3[Br. 3]) $)^{2}$, doch auch sonstiges ${ }^{3}$, der einen Ersatz für fehlende Gesetze bieten konnte. ${ }^{4}$ ) Aber

Manichäern handelnde Teil darum nicht gebracht wird, weil er sich in den Novellen (Val. 18 [Br. 2]) dentlicher findet ("Reliqua pars legis de Manichaeis ideo facta non est, quia in Novellis evidentior invenitur'). Nach Mommsen p. CXXIV, ist dies der einzige Fall, in dem der Kodifikator von einer Konstitution nur dasjenige, dem er Geltung zuschreibt, in das Gesetzbuch aufnimmt: sonst gibt er nämlich überall die Vorlage vollständig und beschränkt sich, das Maf der Geltung in der Interpretation zu verzeichnen.

1) Folgen dieser Art sind der Verlust der Erbfähigkeit in passiven Sinne, ja der Veräußerungsfähigkeit, ferner Intestabilität und Infamie (7, 2. 4. 5. 7). Noch im Justinianischen Kodex (1, 7) kehren einzelne dieser Konstitutionen wieder (4. 7). Andere Gesetze des Titels De apostatis (7) sind temporär (1.6). - 2) Vieles von dem, was Konstitutionen des Titels verordnen, - Verbot der Errichtung von Synagogen und Ausschließung der Juden von 'honor militiae aut administrationis'(22. 25. 27), Verpflichtung der Juden zu munera und zum Dienst in städtischen Korporationen, insbesondere der Kurie (3. 22. 24), - kehrt in der Novelle (\$2. 3. 5. 6) wieder. Auch die Ahndung von Zwang und Verleitung zu dem Zwecke, um einen Christen zum Übertritt ins Judentum zu veranlassen (circumcisio) (19.22. 26) ist der Novelle (\$4) nicht fremd. - ${ }^{\text {s) }}$ Als Strafe der Steinigung, die Juden an den zum Christentum übertretenden Glaubensgenossen verüben, mochte, statt der ersten Konstitution des Titels (8), das Recht der Lex Cornelia (Paul. 5, 25, 1) ausreichend erscheinen. Den zweiten Satz dieser Konstitution, der von der A postasie ins Judentum handelt, wiederholen resp. erläutern Konstitutionen $(7,3$, u. 8,7$)$, die auch ins Breviar $(2,1$ u. 3,2$)$ aufgenommen sind. Für das jüngste (26) aus der Zahl der Strafgesetze von Theod. (22; 9,2 u. 4; 3, 1,5), die sich gegen die Beschneidung nichtjüdischer Sklaven durch den Herrn richten, liefert gleichfalls Paulus (5, 24, 3 и. 4) Ersatz. Sabbatheiligung sanktioniert, statt der ausgefallenen Konstitution unseres Titels (20), ein anderes in das Breviar übergegangenes Gesetz $(2,8,3)$. - 4) Auch mit Bezug auf den im 
nicht alle Ausscheidungen wird man sich auf diesem Wege erklären können: solche sind dann zum Teil derart, daß die Annahme naheliegt, dem Gesetzgeber sei eine antisemitische Tendenz nicht fremd geblieben. ${ }^{1}$ ) Es läßt sich freilich nicht sagen, inwieweit sie AusfluB des Arianismus oder des Westgotentums oder einer allgemeinen Zeitströmung gewesen ist. ${ }^{2}$ )

neunten Titel, 'Ne Christianum mancipium Iudaeus babeat', geregelten Sachverhalt des Erwerbs eines nichtjüdischen, insbesondere christlichen Sklaven durch einen Juden kann man annehmen, daß das Breviar, das ja auch den Titel (4) nicht ausgelassen hat, im wesentlichen das Recht wiedergibt, das für das letzte Wort von Theod. gelten kann. Es besteht darin, daß im Falle des Kaufs Konfiskation des Sklaven, bei Kauf eines christlichen Sklaven zugleich Einziehung des ganzen Vermögens des Käufers stattfindet (2 u. 4). Frei wird der Sklave nur dann, wenn der Herr ihn beschneidet (1) oder der christliche Sklave den Sachverhalt des Erwerbs der Obrigkeit anzeigt (4). Was vom Kauf des christlichen Sklaven, gilt dann auch von anderweitigem Erwerb (4); ja in der Rubrik des Titels heißt es geradezu: ne Christianum mancipium Iudaeus habeat. Die Konstitution, die den beschnittenen Sklaven frei werden läßt, ist in das Breviar $(4,1)$ übergegangen; daß aber nicht bloß der Kauf, sondern auch sonstiger Erwerb verpönt sein und zur Konfiskation führen soll, sanktioniert, neben der genannten Rubrik (4), die Interpretation zu einem andern Text $(3,1,5)$, die folgendermaßen lautet: convenit ante omnia observari, ut nulli Iudaeo servum Christianum habere liceat, certe nullatenus audeat, ut Christianum si habuerit, ad suam legem transferre praesumat. Quod si fecerit, noverit se sublatis servis poenam dignam tanto crimine subiturum.

1) Hierzu gehören die Gesetze, die den Oberen und Priestern Privilegien, darunter auch einen bevorzugten Schutz gegen Beleidigung, eine gewisse Gerichtsbarkeit und das Recht der Festsetzung des Marktpreises beim Handel der Juden zusprechen (2. 4. 8. 10. 11. 13. 15). Ferner die Konstitutionen, die sich gegen Angriffe auf Personen, Behausungen, Synagogen und Zusammenkünfte der Juden wenden (9. 12. 20. 21. 25. 26. 27). Endlich Bestimmungen über Zulassung zor Adrokatur und Rückverweisung von Scheinproselyten (23 u. 24). Anderes läßt sich freilich nicht unter diesen Gesichtspunkt bringen (bezüglich der Tempelsteuer 14. 17. 29; bezüglich Verbots erbrechtlicher Verkürzung der zum Christentum übergetretenen Kinder und bezüglich des Rechts letzterer auf die Falcidia, trotz Inoffiziosität 28 ; bezüglich Verbots des Konkubinats mit Christinnen 6 ; bezüglich exzessiven Betragens der Juden 18 u. 21). - 2) Nach Helfferich, Der westgot. Arianismus S. 68 u. 69 waren die westgotischen Arianer vielmehr judenfreundlich und stand Theologie und Kirchenwesen bei ibnen stark unter jüdischem Einfluß. Ein überzeugender Beweis ist indessen nicht erbracht. 
5. Nachdem hiermit der Versuch gemacht worden ist, die Motive festzustellen, die den Gesetzgeber der westgotischen Lex Romana zur Ausscheidung von Texten von Theod. XVI veranlaßt haben, sei dann noch zum Schluß der im Vergleich mit der Vorlage so überaus dürftige Rechtsinhalt ins Auge gefaßt, der davon im Breviar übriggeblieben ist. Er erscheint in doppelter Gestalt, einmal in der originalen, die Vorlage wiedergebenden und sodann in derjenigen der Interpretation, soweit der Gesetzgeber, was wiederholt geschieht, sich nicht begnügt, zu bemerken, daB der Text der Vorlage keiner Erläuterung bedürfe. Es wird die Freiheit des Klerus von jedwedem munus sanktioniert $(1,1)$ : die Interpretation umschreibt die Immunität als Befreiung von jedem Officium und von jedem Servitium. ${ }^{1}$ ) Diesem Standesrecht steht dann als Standespflicht gegenüber $(1,6)$, mit keiner anderen Person weiblichen Geschlechts als Mutter, Schwester, Tochter und der vor Eintritt in den Klerus angetrauten Ehefrau Hausgemeinschaft zu unterhalten. Versagung der Testierfähigkeit wird gegen die Apostasie zum Paganismus, Strafe bzw. Vermögenskonfiskation gegen den Übertritt zum Judentum verordnet $(2,1 ; 3,2)$, umgekehrt den zum Christentum übertretenden Juden Schutz gegen Angriffe von seiten ihrer Glaubensgenossen zugesichert $(3,1)$. Wird ein Sklave von dem Käufer, der Jude ist, beschnitten, so gewinnt er die Freiheit $(4,1)$. Was dann noch übrigbleibt, betrifft das Verfahren in Rechtssachen, bei denen Personen geistlichen Standes beteiligt sind. Einmal $(1,5)$ den seine Stellung aufgebenden

1) Sie lautet: lex haec speciali ordinatione praecipit, ut de clericis non exactores, von allectos facere quicumque sacrilega ordinatione praesumat, quos liberos ab omni munere, id est ab omni officio omnique servitio jubet ecclesiae deservire. Der Sachverhalt der Befreiung von den Geschäften eines Exactor und Allectus soll wohl wiedergeben, was die in Theod. unmittelbar vorangehende (2, 1), in Breviar aber fehlende Konstitution besagt, wenn sie sich gegen diejenigen wendet, die die Kleriker zu 'nominationes' und 'susceptiones' heranziehen. Die Aufnahme der Konstitution ins Breviar verbot sich aus dem Grunde, weil sie den besonderen Sachverhalt im Auge hat, daf durch Betreibung der Häretiker der Klerus der katholischen Kirche zu den genannten Geschäften herangezogen wird (Haereticorum factione conperimus ecclesiae catholicae clericos vexari). 
oder vom Bisch of wegen schlechten Wandels abgesetzten Kleriker, der dann unwiderruflich und, je nach seiner Herkunft und der Größe seines Vermögens, der Kurie oder einer städtischen Korporation bzw. zu einer für ihn sich eignenden Dienstleistung überwiesen wird. ${ }^{1}$ ) In einem zweiten Gesetze $(1,4)$ ist verordnet, daß der von seinen Mitbischöfen abgesetzte Bischof, der die offentliche Ruhe und Sicherheit in Gefahr bringt, indem er die Wiedereinsetzung in sein A mt betreibt, den früheren Bischofssitz zu meiden hat und auch nicht durch kaiserliches Reskript seine Wiederherstellung erzielen kann: erinnert man sich, da 6 nicht lange vor der Publikation des Breviars wiederholt katholische Bischöfe, unter der Anschuldigung der Konspiration mit den Franken, vom Bischofssitz entfernt oder abgesetzt, auch wohl durch den König zurückberufen wurden ${ }^{2}$ ), so kann es nicht für unwahrscheinlich gelten, daß auf die Aufnahme der Konstitution in das Gesetzbuch die geschichtlichen Vorgänge Einfluß geübt haben. Endlich bezieht sich eine Dreizahl von Konstitutionen auf das Forum (1,2 u. 3; 5, 1). Ihr Rechtsinhalt besteht hierin, daß geistliche Streitsachen bzw. die unter Klerikern über die Religion sich abspielenden Sachen vor das geistliche Gericht, dagegen Kriminalsachen vor den bürgerlichen Richter gehören: das geistliche Gericht

1) Die Interpretation zeigt einzelne leise Abweichungen, insbesondere, dafi sie die Decem primi curiales, die für die Verwendung des Klerikers im städtischen Dienst haften, durch Kurialen schlechthin ersetzt. Mit Bezug auf die Utberweisung an den städtischen Dienst sagt der Gesetzestext: pro hominum qualitate et quantitate patrimonii vel ordini suo vel collegio civitatis adiungatur: modo ut quibuscumque apti erunt publicis necessitatibus obligentur; hingegen heift es in der Interpretation: (ut,) si ita et natalibus et facultatibus est idoneus, eum inter ipsos curiales officium suum inplere conpellat. Si autem infima persona est, inter collegiatos eum observare, vel ad quod aptus fuerit, in publico servire lex ista constituit. Noch deutlicher als im Text wird hier mit dem Fall gerechnet, daß ein Kleriker wohlhabend ist. Es mag dann nach Auffassung der Interpretation auch die Aufnahme von wohlhabenden Personen in den Klerus zulässig gewesen sein, gegen den Standpunkt von Konstitutionen von Theod. (2, 3. 6. 11. 17), die darum nicht aufgenommen sein werden (vgl. S. $70^{1}$ ). $\left.-{ }^{2}\right) \mathrm{Vgl}$. A schbach, a. a. O. S. 168. Der Schriftsteller weist auf Gregor Hist. Franc. 2, 36 u. 10, 31. 
ist bei einem Streite unter Klerikern der Bischof, besteht aber bei Anklage eines Bischofs, auf welchen Sachverhalt sich ja auch der soeben erwähnte Text $(1,4)$ bezieht, aus den übrigen Bischöfen. ${ }^{1}$ )

\section{II.}

1. Der Breviarauszug ist nicht der einzige Auszug von Theod. XVI, den wir besitzen: es gibt außerdem noch verschiedene (vgl. S. 68). Und zwar haben sie eine gemeinsame

1) DaB die hier gegebene Charakterisierung zutrifft, kann m. E. gar nicht zweifelhaft sein. Zwei der genannten Konstitutionen, die eine $(1,3)$ von Valens, Gratian und Valentinian, die andere $(5,1)$ von Arcadius und Honorius sprechen die Bescbränkung der bischöflichen Jurisdiktion auf geistliche Sachen, die Kompetenz des bürgerlichen Richters in den andern, bzw. den Kriminalsachen, ganz unzweideutig aus. Nur ist noch hinzuzufügen, daf es nach der einen $(1,3)$ 'negotia ecclesiastica', 'ad religionis observantiam pertinentia' gibt, die den Charakter von 'levia delicta' tragen, und daß für das Verfahren in geistlichen Sachen das bürgerliche als Vorbild dienen soll: die Interpretation gibt indessen weder den einen noch den andern Sachverhalt wieder. Die dritte Konstitution (1,2) wird durch letztere, wie folgt, erläntert: specialiter prohibetur, ne quis audeat apud iudices publicos episcopum accusare, sed in episcoporum audientiam perferre non differat, quidquit sibi pro qualitate negotii putat posse conpetere, ut in episcoporum aliorum iudicio, quae adserit contra episcopum, debeant definiri. Daf damit nicht, als Ausnahme, das Kriminalverfahren gegen Bischöfe dem geistlichen Gericht zugewiesen werden soll, vielmehr auch hier nur an 'negotia ecclesiastica' gedacht ist, läkt sich schon nach der Fassung des Textes vermuten, wird aber ganz zweifellos, wenn man erwägt, dac die Novelle Valentinians III. (35 [Br. 12]) in das Breviar aufgenommen ist; unter Berufung auf die genannte Konstitution von Arcadius und Honorius wird nämlich hervorgehoben, daf die Bischöfe, außer in Sachen der Religion, keine gerichtliche Kompetenz besitzen (pr. "constat episcopos [et presbyteros] forum legibus non habere nec de aliis causis secundum Arcadii et Honorii divalia constituta, quae Theodosianum corpus ostendit, praeter religionem posse cognoscere') und bei Kriminalanklagen von Bischöfen, abgesehen von der Zulässigkeit der Stellvertretung in gewissen Fällen, das gemeine Recht in Anwendung kommt. Es war daher auch kein Platz für Konstitutionen von Theod. XVI, die, indem sie eine Verhandlung von Kriminalsachen der Kleriker vor dem Bischof voraussetzen, das bezügliche Verfahren regeln $(2,41)$, oder die im Sinne einer völligen Befreiung der Kleriker von der bürgerlichen Gerichtsbarkeit gedeutet werden konnten $(2,47)$ : sie sind daher in das Gesetzbuch nicht übergegangen. 
Eigenschaft: wenn nämlich der erstere in einem oben (vgl.S. 72f.) ins einzelne entwickelten Sinne als ein von arianischen Tendenzen erfülltes Produkt gelten darf, so haben bei der Abfassung letzterer vielmehr katholische Tendenzen obgewaltet. Im übrigen sind sie freilich sehr verschieden: ein besonders wesentlicher Gegensatz besteht aber darin, daß sie entweder bestimmt waren, den Breviarauszug von Theod. XVI zu erweitern und zu ergänzen, oder nicht, mögen sie auch nachträglich diese Verwendung erhalten haben oder wenigstens jenem Auszug angereiht worden sein. Es soll zunächst von den ersteren die Rede sein, die keine umfassende Darstellung erfordern und an Bedeutung den ohne Hinblick auf das Gesetzbuch Alarichs veranstalteten Auszügen weit nachstehn. Mit Bezug auf ihre Entstehungsverhältnisse läßt sich von vornherein sagen, daß die Abfassung der Auszüge in den freilich sehr umfassenden Geltungsbereich des Gesetzbuches, das gotische Spanien und ferner Gallien, fällt: Gallien nicht allein, soweit es zum tolosanischen Reiche gehörte, da ja das Breviar im Frankenreich auch außerhalb des ehedem westgotischen Gebietes frühzeitig sich durchsetzte. ${ }^{1}$ ) Die Herrschaft des Breviars, die ja in Spanien bezw. im gotischen Reiche eine Dauer von nicht mehr als anderthalb Jahrhunderten hatte, indem König Reccessvind ihr durch Einführung seines Gesetzbuchs ein Ende machte, bezeichnet dann zugleich auch die zeitliche Grenze. Des weiteren erseheint aber auch die Entstehung dieser Produkte im Hinblick auf den - sagen wir - arianischen Charakter des Breviarauszugs sehr begreiflich; denn letzterer konnte den Katholiken, die religiös und kirchlich interessiert waren, nicht genügen. Keine Macht aber war besser imstande als eben der religiös und kirchlich in ganz besonderem Maße interessierte Kreis, oder mit anderen Worten, die Kirche im Wege der Hinzufügung von Rechtsstoff von Theod. XVI bzw. durch Angliederung weiterer Auszüge an den Breviarauszug, Abhilfe zu schaffen: denn niemand verfügte über ein größeres Maß der zur Verrichtung solcher Arbeit erforderlichen geistigen und selbst mechanischen Hilfsmittel. Es

1) Vgl. Conrat (Cohn), Geschichte d. Quellen u. Liter. d. Röm. Rechts i. früh. Nittelaiter 141 u. 42. 
mußte in der Tat genügen, auf dem angegebenen Wege vorzugehen: denn der arianische Charakter bestand, wie wir sahen, nicht sowohl in dem Charakter der ausgewählten Stücke als vielmehr, wie z. B. am deutlichsten die Ausscheidung des Titels De fide catholica und der auf die Ketzer bezüglichen Texte vor Augen stellt, die ja dem Auszug insbesondere jenen arianischen oder wenigstens antikatholischen Charakter gibt, in der Auswahl. Was wir nun von Auszügen dieser Art besitzen, ist durchaus verschieden; denn während einmal die durch den Zusatz aus Theod. XVI entstandene Erweiterung eine ganz geringfügige ist, wird ein anderes Mal daraus Theod. XVI vollständig: ein dritter Fall steht in der Mitte. Die Hinzufügung beschränkt sich nämlich in zahlreichen Handschriften auf den letzten Text von Theod. $\left.(11,3)^{1}\right)$, der allerdings nicht weniger als alles, was jemals von den römischen Kaisern mit Bezug auf die katholische Ordnung (catholica lex) festgesetzt worden ist, bestätigt und befestigt. ${ }^{2}$ ) Umgekehrt liefert der Breviarkodex Epored. 35 Saec. IX ${ }^{3}$ ) Theod. XVI vollständig, indessen nicht im Wege des Ersatzes des Breviarauszugs durch Theod., sondern indem er titelweise den Texten des Breviarauszugs die in ihm nicht aufgenommenen Konstitutionen von Theod. XVI anreiht. Durchgeführt ist indessen diese Ordnung ${ }^{4}$ ) lediglich im zweiten

1) Vgl. das Nähere bei Mommsen p. XCII. $-{ }^{2}$ ) Daneben findet sich in verschiedenen Handschriften ein Gesetz (4) aus dem Titel ' $\mathrm{Ne}$ Christianum mancipium Judaeus habeat' (9), mit der Inskription 'Idem' aus Theod. $-{ }^{3}$ ) Vgl. Mommsen p. LXVII. LXVIII. CXXII sq. CXXXV. Weitere Handschriften (Cod. Rosnyanus u. Cod. Paris. 4406 f. 1-56) sind aus ihm abgeschrieben (vgl. Mommsen p. LXVIII-LXX). Was die Heimat des Cod. Epored. anlangt, so mag man aus dem gegenwärtigen Verwahrungsort (Domkapitelbibliothek von Irrea) schließen, dafis er aus dem angrenzenden Burgund stammt. Im Punkte der Textesgestaltung von Theod. XVI besitzt die Handschrift grofe Verwandtschaft mit der Überlieferung der Sammlung von Codd. Phillipps. u. Paris. (auch mit dem Auszug von Cod. Paris. 4403) und bildet mit ihnen eine Gruppe (vgl. Mommsen p. CXXII sq.; Krüger, Savigny-Zeitschrift XXVI, 325): auch dieser Umstand läßt sich für Abfassung der Handschrift (bzw. der Gestaltung von Theod. XVI, wie ihn die Handschrift bietet) in der genannten Landschaft verwerten (vgl. S. 125 u. 95). Gallischen Ursprung des Cod. nimmt auch ed. P. Meyer p. XXXII an. 4) Vgl, das Nähere bei Mommsen p. XC u. XCI erste Spalte, wo Cod. Epored. mit $\mathrm{E}$ und in der Breviarreihe von Titel 2-5 mit [E] bezeichnet ist. 
Titel, der aber hier, wie im Breviar, die erste Stelle (I) einnimmt. Die folgenden Titel, II-VI, sind die vollständigen Titel 1. 3-6 von Theod, während unter den Ziffern VII-X die Titel 7. 8. 9. 11, indessen nur im Umfang der entsprechenden Breviartitel (2-5) und unter Ziffer XI die ersten drei Sirmondischen Konstitutionen mit der Rubrik 'De episcopali iudicio', erscheinen. ${ }^{1}$ ) Zwischen den Abschnitten VI und VII sind nun aber, aus der Reihe herausfallend, ohne jede Ziffer und, im Gegensatz zu den bezifferten elf Abteilungen, auch ohne die Rubriken, Titel 7-11 von Theod. vollständig aufgenommen. Insofern auch hier (vgl. S. 102) Texte einer Breviarreihe und einer Theodosianusreihe unterschieden werden können, muß man sagen, daß die Texte, die den Breviartiteln 2- $\mathbf{5}$ angehören, in beiden Reihen auftreten: es scheint dabei, da $B$ die Breviarreihe wirklich aus dem Breviar geschöpft hat ${ }^{2}$ ), wie ja auch die Interpretation nicht fehlt. Eine Leistung von Bedeutung kann in dem, was Cod. Epored. bringt, nicht erblickt werden, wie sich ja auch ein in ihrer Benutzung sich kundgebender Erfolg kaum nachweisen läßt ${ }^{3}$ ):

1) Vgl. Mommsen p. CCCLXXIX. $\left.-{ }^{2}\right)$ Dies ist von vornherein wahrscheinlich, da Cod. Epored. eine Breviarhandschrift ist und die Texte in den Breviartiteln (Abschnitt VII-X) außer Verbindung mit solchen aus Theod. erscheinen: es wird aber sicher durch den Umstand, daß die Inskriptionen $(7,3[\mathrm{Br} .2,1] ; 8,5$ u. 7 [Br. 3,1 u. 2) diejenigen nicht von Theod. (Idem), sondern des Breviars sind. Was die Breviarreihe in dem ersten (in Theod. zweiten) Titel anlangt, so haben einige Texte gleichfalls nicht die Inskription von Theod. (Idem), sondern diejenige des Breviars (2 [Br, 1]; 12 [Br. 2]), während andere das Idem des Theod., gegen das Breviar, beibehalten haben (35 [Br. 4]; 39 [Br. 5]; 44 [Br. 6]): ich nehme an, daks sich letztere Verschlimmbesserung aus der der Handschrift eignen Verwertung von Theod. für die Kritik des Textes erklärt (vgl. Mommsen p. CXXXV). Die Bemerkungen betreffend den Text und die Inskriptiones des Cod. Epored. gründen sich auf die textkritischen Angaben in ed. Mom msen. - ${ }^{3}$ ) M. E. kommt die Eventualität einer Benutzung des Cod. Epored. nur hinsichtlich der gegen Ende des 11. Jahrbunderts verfaßten Schrift ' $D$ e unitate ecclesiae conservanda' (MG. Libelli de lite II, 184 sq.), über deren Verwendung Römischen Rechts v. Wret s c h $\mathrm{r}$ o bei Mommsen p. CCCXLIV u. CCCXLV, orientiert, in Betracht. In dem neunten Kapitel des ersten Buchs (a.a. O. p. $196 \mathrm{sq}$.) heifst es: multa sunt Arcadii imperatoris privilegia, quae recipit ecclesia, utpote sibi valde necessaria, sicut testatur liber christianorum imperatorum de fide catholica. Es wird dann eine größere Zahl von Stellen aus Theod. 
eine Erweiterung des Breviarauszugs zur Vollständigkeit von Theod. XVI war leicht zu vollziehen, ist aber überdies in unserer Handschrift, wie die Beschreibung lehrt, in möglichst unvollkommener Weise vollzogen worden; dazu kommt, daß, wenn schon nicht jeder Auszug von Theod. XVI, wie die Sammlung zeigt, die in den Codd. Phillipps. 1741 und Paris. 12445 (ehedem Sangerm. 366) vorliegt, sich zur Aufnahme in das Breviar eignete, (vgl. S. 103f.), noch viel weniger es mit dem vollständigen Theod. XVI der Fall ist. Besonders eigenartige Züge weist der dritte Auszug auf. ${ }^{1}$ ) Er findet sich in der Breviarhandschrift Cod. Paris. 4403 aus dem Ende des 8. oder dem Beginn des 9. Jahrbunderts, die im südlichen Gallien geschrieben sein mag. ${ }^{2}$ ) Theod. XVI des Breviars ist nämlich

XVI, meist in mehr oder minder freier Fassung, aufgeführt, darunter auch solche, die dem Auszug von Cod. Phillipps. und Cod. Paris. nicht angehören und nirgends anders als in Theod. XVI selbst bzw. in Cod. Epored. sich nachweisen lassen (z. B. 2, 25; 5, 24 u. 62), wobei mehrfach Texte dem Arcadius (und Honorius) zugeschrieben werden, die nicht auf ihn (resp. sie) inskribiert sind. Gegen die Benutzung des Cod. Epored. spricht indessen, daB die Bezeichnung der Quelle mit 'liber christianorum imperatorum de fide catholica' vermuten läßt, dem Autor habe lediglich Theod. XVI und dazu in einer Gestaltung, die mit dem Titel 'De fide catholica' beginnt, vorgelegen, was gerade für Cod. Epored. nicht zutrifft. Es mag dem Verfasser einfach eine separate Überlieferung von Theod. XVI vorgelegen haben. Die beregte Zuschreibung von Texten an Arcadius (und Honorius) läßt sich nicht für die Annahme der Benutzung eines Auszugs benutzen, da sie schwerlich auf einer Inskriptionenversetzung der Vorlage beruht. Vielmebr wird sie sich damit erklären, daß der Verfasser sich zur Wiedergabe von Rechtsinhalt, den er in einem Gesetze des Arcadius vorfand, der Fassung des Gesetzes eines anderen Kaisers bedient, z. B. Rechtsinhalt von 2, 29 u. 30 mit Worten Valentinians III. (2, 47 pr.), von 5, 20 u. 29 mit Worten desselben Kaisers $(5,62)$ wiedergibt, oder daß er auf Grund der auf Arcadius inskribierten Sanktionierung der Verfügungen seiner christlichen Vorgänger $(2,29)$ ersterem auch ältere Kajseraussprüche zuschreibt $(1,2$ u. $3 ; 2,25)$.

1) Vgl. Mommsen p. XCI. Die Handschrift wird mit dem Buchstaben $\mathrm{L}$ bezeichnet. - ${ }^{2}$ ) Eine Beschreibung der Handschrift bei Haenel p. XLIX and Mommsen p. LXXVII. LXXVIII. CXXIIsq. CXXXVI. Während letzterer die Herkunft als unsicher bezeichnet, nimmt Haenel Abfassung im südlichen Frankreich an. Auch Hinzufügungen in den Breviartext werden südgallischen Ursprungs sein (vgl. S. 95). Die in Hand schriften der Collectio Anselmo dedicata vorliegende Editions- 
hier, wie folgt, gestaltet. Der erste Titel unter der Rubrik 'De episcopis aecclesiis et episcopis" und der siebente, "De apostatis', sind lediglich die entsprechenden Breviartitel (1 und 2). Dazwischen somit als zweiter bis sechster Titel, finden sich die im Breviar fehlenden Titel von Theod. 'De fide catholica' (2), 'De monachis' (3), 'De his qui supra (sic!) religione contendunt' (4), 'De haereticis' (5), 'Ne sanctum baptisma iteretur' (6) mit einzelnen Konstitutionen vertreten, während der letzte Breviartitel, übrigens mit Hinzufügung der beiden im Breviar fehlenden Texte, den Schluß resp. den achten Titel, bildet. Mit dem Breviar hat danach diese Repräsentation von Theod. XVI das Fehlen des Titels 'De paganis sacrificiis et templis' (10) gemein, während umgekehrt die im Breviar vertretenen Titel ( 8 und 9), die sich auf die Juden beziehen, ausgefallen sind. Es handelt sich sonach hier eigentlich nicht, wie in den bisherigen Fällen, darum, daß mit dem Breviarauszug ein anderer verbunden ist, der ersteren spärlich oder bis zur Vollständigkeit von Theod. bzw. über diese hinaus erweitert und ergänzt, sondern hier vertreten vielmehr ein Auszug aus dem Breviarauszug und ein anderer Auszug von Theod. Theod.XVI der Lex Romana. Daß auch dieses Produkt katholische Tendenzen verfolgt, ergibt sich aus der Aufnahme des Titels De fide catholica, mit der Proklamierung des katholischen Glaubensbekenntnisses (2), und der im Breviar fehlenden Gesetze des letzten Titels (2 und 3) (vgl. S. 74), sowie einer gegen die Wiedertaufe gerichteten Konstitution $(6,1)$. Bemerkenswert ist, daß aus dem Titel De fide catholica (1), neben der Konstitution des Theodosius, das gegen die Verwendung der Christen zum Schutz der heidnischen Tempel gerichtete Gesetz (1) vorhanden ist, was auf sehr frühe Entstehung weist. Die Ketzer, gegen die sich die dem Titel De haereticis (5) entlehnte Konstitution (3) wendet, sind die Manichäer. Man wird dann mit der Annahme rechnen dürfen, daß uns die Breviarhandschrift eine

formel (eine unbekannte annähernde Version in Cod. Berol. Lat. Fol. $636 \mathrm{f}$. $1^{\vee}$ ), von der, wie Patetta, Arch. giurid. XLVII, 24 u. 26, zeigt, die ersten Zeilen der zu Beginn nicht vollständigen Pariser Handschrift (vgl. Mommsen p. LXXVIII sub N. 1) das Schlußstück liefern, wird wenigstens für ein Produkt gallischen Ursprungs gelten können. 
in der Provence hergestellte und nicht lange nach ihrem Übergang in fränkische Herrschaft fallende Darstellung von Theod. XVI bzw. von Theod. überhaupt erhalten hat. Wenn sich nämlich in Theod. Einschaltungen finden, die auf die Lex Romana Burgundionum und das Edictum Theoderici zurückgehen ${ }^{1}$ ), könnte man annehmen, in diesen Stücken residuäre Erscheinungen der Rechtsbücher vor sich zu haben, die vor der Angliederung der Landschaft an das fränkische Reich i. J. 536, womit auch der Anschluß an das Breviar eingeleitet wurde, successive die Provence beherrschten. ${ }^{2}$ ) Für Entstehung in der Provence spricht aber auch der Standpunkt des Auszugs in Sachen der Häresien: er verrät südgallische Herkunft, insofern er sich mit dem Breviar, tolosanischen Ursprungs, von allen Ketzereien allein gegen die Manichäer wendet (vgl. S. 79); er legt andererseits Entstehung auf einem Gebiete von ganz überwiegender römischer Bevölkerung nahe ${ }^{3}$ ), wenn er, trotz katholischen Bekenntnisses, unterläBt, gegen die Arianer anzukämpfen. $\left.{ }^{4}\right)^{5}$ )

2. Was die Auszüge anlangt, die nicht zur Ergänzung und Erweiterung des Breviars bestimmt waren, so liegt zu-

1) Vgl. Mommsen p. LXXVIII sub 3 u. $6 .-{ }^{2}$ ) Sie gehörte von 500 bis 510 zum burgundischen, seitdem bis 536 zum ostgotischen Reich, so die Karte bei Dahn (vgl. S. $73^{3}$ ), III zu S. 70, was freilich mit bezug auf Burgund nur cum grano salis gilt. - 3) Vgl. Kiehner, Verfassungsgesch. der Provence S. 27. - *) A uch bei Aufnahme der Konstitution, die sich gegen die Wiedertaufe wendet, braucht nicht an die Arianer gedacht zu sein. Auch die Sekte der Bonosiaci oder Bonosianer, die im südlichen Gallien und in Spanien während der Zeitläufte, in die die Anfertigung des Auszugs fällt, eine Rolle spielen, verlangten vonden konvertierenden Christen eine zweite Taufe (vgl. Realencykl. f. prot. Theol. ${ }^{3}$ III, 314f.). - 5) Bei Verwertung der aufgenommenen Texte zur Bestimmung des Altersverhältnisses ist nicht mit dem Umstande gerechnet, dak der Titel 'De monachis', der nichtallein im Breviarauszug, sondern auch in den sonstigen Auszügen fehlt, aufgenommen ist. Man mag diesen Sachverhalt im Sinne einer Bestätigung der katholischen Tendenzen des Produkts oder etwa auch zu der Annahme verwenden, dak es in einem Kloster seinen Ursprung hat. Auffallend ist in dem katholischen Produkt die Aufnahme der ersten Konstitutionen des Titels (4) De his qui supra religione contendunt', da dieser Text sich dagegen wendet, daßs eine Religionsgemeinschaft sich ausschließlich geltend machen will. Aus dem Fehlen der Breviartitel ( 3 u. 4), die von den Juden handeln, wird man schwerlich etwas schliefen dürfen. 
nächst die Begrenzung der Entstehungsverhältnisse weniger günstig, als in dem bisher erörterten Falle. Denn als Entstehungsgebiet wäre an und für sich auch Italien - mit einer Entstehung im Osten braucht man, im Hinblick auf ihre Überlieferung, schwerlich zu rechnen - in Betracht zu ziehen, allerdings nur für das Jahrhundert, das von der Publikation von Theod. bis zur Einführung der Justinianischen Kodifikation verstrich, da man sich hernach schwerlich mehr mit Theod. beschäftigt haben wird. Was die Eventualität einer Entstehung auf nichtitalischem Boden betrifft, so könnte man meinen, daß ein solcher Auszug am ehesten nur außerhalb des tolosanischen Reiches entstanden sein werde, insbesondere auch außerhalb der Grenzen der westgotischen Herrschaft auf gallischem Boden, sei es zu der Zeit, als die alten Quellen, zu denen Theod. gehörte, noch in Kraft waren, sei es bereits unter der Geltung des Breviars, die ja, vom westgotischen Territorium abgesehen, keine auf Gesetz beruhende und keine exklusive war: innerhalb des letzteren sei dagegen ein anderer als der Breviarauszug ausgeschlossen gewesen, weil der westgotische Gesetzgeber seiner Lex Romana ausschließliche Geltung zuschreibt und somit Theod. außer Kraft gesetzt hat, so daß nur die Eventualität einer Entstehung vor Publikation des Breviars in Betracht käme. ${ }^{1}$ ) Ich glaube, daß diese Erwägung, die konsequent dazu führen müßte, auch für die Ergänzungen und Erweiterungen, die das Breviar erfahren hat, Abfassung auf westgotischem Boden von vornherein auszuschließen, nicht Stich hält, wie uns sogar Zusätze zum Breviar, wenn auch nicht in Theod. XVI, erhalten sind, die Einfügung auf westgotischem Boden verraten $^{2}$ ): insbesondere aber ist ganz unwahrseheinlich, daß

1) Kaum die einer Entstehung nach Außerkraftsetzung des Breviars durch Reccessvind. - ${ }^{2}$ ) Ich habe Erweiterungen des sogenannten Codex Vesontinus und einer anderen Handschrift (Vatic. Reg. 1050) im Auge, die einzelne Titel der Sentenzen betreffen (vgl. ed. Krüger a. d. S. $80^{1}$ a. O., p. 44, und Savigny-Zeitschrift G. A. XXIX $240 \mathrm{f}$.). Ältestes gotisches Recht betreffend Adulterium und Verknechtung der Frauen bei Buhlschaft mit fremden Sklaven weist nämlich auf Verwertung von römischem Recht außerhalb der Kodifikationen, insbesondere auch von Text der Sentenzen, der nicht ins Breviar übergegangen ist. 
m an aus Respekt vor dem arianischen Kodifikator Theod.XVI in katholischen Kreisen unberührt gelassen haben wird, zumal nachdem das Königtum, seit 586, selbst katholisch geworden war. Nicht geringere Unsicherheit als mit Bezug auf die Örtlichkeit besteht hinsichtlich der Zeit der Entstehung: wenn man im allgemeinen annehmen kann ${ }^{1}$ ), dab die Beschäftigung mit Theod. selbst nicht weiter als in den Beginn des 10. Jahrhunderts reicht, so ist doch wohl möglich, daß Theod. XVI allein, insbesondere in getrennter Überlieferung, noch darüber hinaus bekannt geblieben ist. ${ }^{2}$ ) Hingegen scheint es auf der Hand zu liegen, was den Anlaß zur Veranstaltung von Auszügen aus Theod. XVI gegeben haben wird: bereits ist darauf hingewiesen worden (vgl. S. 70 u. 71), daß Theod. sich die Aufgabe stellte, ohne Rücksicht auf praktische Verwendbarkeit und wiederholte Wiedergabe eines Rechtsinhalts die Gesetzgebung der christlichen Kaiser zu sammeln; diesem die Benutzung für praktische Zwecke erschwerenden Sachverhalt durch eine Auswahl abzuhelfen, mußte für ein nützliches Unternehmen gelten, wobei in Betracht kommt, daB aus dem Gesichtspunkte der Beschränkung auf das praktisch Verwertbare das $\mathrm{MaB}$ des auszuscheidenden Rechtsstoffes wiederum von den Entstehungsverhältnissen abhängig war und sich im allgemeinen steigerte, je weiter stch die Abfassungszeit des Auszugs von der Abfassungszeit der Konstitutionen von Theod. entfernte. Indessen trifft, sonderbarerweise, dieses Motiv, wie es scheint, gerade nicht zu auf den einen der beiden Auszüge von Theod. XVI, die unter die

(vgl. Zeumer, N. A. XXIII, 454 u. 455 , u. Brunner [vgl. S. $125^{2}$ ] J, $488^{25}$ ). Weun sich nun an den aa. 00 . der Sentenzentitel De adulteriis $(2,26$, ed. Krüger) ergänzt, ein Titel $\mathrm{De}$ mulieribus quae se servis alienis iunxerint (2, 21 a a. a. O.) eingesehaltet findet, so wird hierbei die Absicht obgewaltet haben, aus Paulus Quelle und Seitenstück der entsprechenden Normen gotischen Rechts zur Verfügung zu stellen.

1) Näheres in 'Geschichte der Quellen' (vgl.S. 90') I, 91 f. und im wesentlichen damit übereinstimmend bei Mommsen p. LIX sq., CIII u. CIV, wo noch (p. LXIV) bemerkt ist, daks ein Cod. Montispess. Saec. IX mehrere Texte aus Theod. entlehnt. Der Beginn des 10. Jahrhunderts als äuferstes Datum ist wegen der Solmser Handschrift angenommen (vgl. S. 98). $-{ }^{2}$ ) Aus einer solchen Utberlieferung mag die Schrift 'De unitate ecclesiae conservanda' noch gegen Ausgang des 11. Jahrhunderts geschöpft haben (vgl. S. $92^{3}$ ).

Zeitschrift für Rechtsgeschichte. XXXII. Kan. Abt. L. 
hier zu behandelnde Kategorie fallen. Es ist dies derjenige, der einen Teil eines weiteren Auszugs, nämlich von Buch 9 bis Buch 16, ausmacht und in einer Solmser Handschrift Saec. IX/X von offenbar gallischer Herkunft erhalten ist. ${ }^{1}$ ) Vom 16. Buche sind nicht mehr als vier Texte $(2,31.34 .38 .47)$ ausgezogen. Sie reichen indessen aus, um den katholischen Ursprung sicherzustellen: es ist nämlich der Text (31) aufgenommen, der den katholischen Kirchen gegen sakrilegischen Einbruch besonderen Schutz gewährt, während die übrigen drei Konstitutionen insbesondere die Aufrechthaltung der Privilegien der Kirche verlangen und für den Gerichtsstand vor dem geistlichen Richter eintreten. Auch in einzelnen sonstigen Konstitutionen des weiteren Auszugs der Handschrift tritt christliches und kirchliches Interesse zutage (15, 8, 1 u. 2). Was dessen Entstehungsverhältnisse anlangt, so könnte es zunächst scheinen, daß er zwar nicht vor dem 6 . Jahrhunderte, immerhin in früher Zeit und zwar in Gallien, wenn auch schwerlich im Gebiete des Reiches von Toulouse, abgefaßt ist. ${ }^{2}$ ) Für die Determinierung in zeitlicher Hinsicht kommt nämlich in Betracht, daß der Auszug auf die vatikanische Handschrift von Theod. gallischen Urprungs, die noch im 6. Jahrhundert geschrieben ist, zurückgeht ${ }^{3}$ ), während er andererseits überwiegend Konstitutionen enthält, die zum römischen öffentlichen Rechte gehören, unter andern auch öffentliche Verhältnisse der Stadt Rom regeln (z. B. 14, 5, 1 und 14, $15,1)$, und darum in späteren Zeiten keine praktische Verwertung finden und schwerlich juristischem Interesse begegnen

1) Vgl. Savigny-Zeitschrift, R. A. IX, 389-392, u. Mommsen p. LVII. Angabe des Bestands am ersten Orte S. 390 u. 391 (es muf heiken 9, 3, 3. 4 statt 9, 3 34) und bei Mommsen, a. a. O._- ${ }^{2}$ ) Diese Auffassung ist etwa vertreten a. d. N. 1 a. O. (Savigny-Zeitschrift) S. 392 u. Geschichte d. Quellen I, 92 ${ }^{2}$. Nur ist aus dem Verhältnis zum Vatikanischen Kodex (vgl. den Text sofort) nicht der Schluß gezogen, daf der Auszug jünger ist als jene Handschrift. Weil er nun aber Konstitutionen enthält, die dem römischen öffentlichen Rechte angehören, wurde die Folgerung gezogen, dak er, d. h. der angenommene Archetyp der Solmser Handschrift, von dem letztere nur eine Abschrift sei, weder auf westgotischem Boden, noch im Frankenreich, sondern im sogenannten weströmischen Reiche Galliens seine Heimat hat. - ${ }^{3}$ ) Vgl. Mommsen p. XLVI und Traube p. III. 
mochten. Die Annahme einer Entstehung auf gallischem Boden gründet sich auf den gallischen Ursprung ebenso der Vatikanischen wie der Solmser Handschrift, ihre Herkunft aber von außerhalb der Grenzen des - man darf sagen - ehemaligen Reichs von Toulouse - denn der Auszug wird füglich nach dem Jahre 506 verfertigt sein - auf die Erwägung, daß hier nach dem Inkrafttreten des Breviars schwerlich von neuem der ganze, in Wahrheit der halbe Theod. ausgezogen sein wird. Diese Ansicht setzt jedoch voraus, daß wir in der Solmser Handschrift nicht den Archetyp des Auszugs, sondern vielmehr die auf ihn zurückgehende, aber um Jahrhunderte jüngere Handschrift besitzen. In Wahrheit scheint es indessen, daß wir ein direkt aus der Vatikanischen hergestelltes Produkt bzw. ein Produkt des gallischen Schreibers Saec. IX/X vor uns haben ${ }^{1}$ ), der sich zu seiner Abfassung durch ein Motiv bestimmen lieb, das dann freilich auch, soweit ich sehe, eine Schlubfolgerung auf den Entstehungsort nicht leicht zuläßt. Der Auszug entlehnt nämlich überwiegend seinen Stoff aus Titeln mit Rubriken der Art, wie De thesauris $(10,18)$, De vestibus holoveris et auratis $(10,21)$, De alimentis quae inopes parentes de publico petere debent $(11,27)$, De medicis et professoribus $(13,3)$, De honoratorum vehiculis $(14,12)$, De annonis civicis et pane gradili $(14,17)$, De pretio piscis $(14,20)$, De expensis ludorum (15, $9)$, De venatione ferarum $(15,11)$, De gladiatoribus $(15,12)$. Und zwar ist es gewöhnlich nur die erste Konstitution, die er den Titeln entnommen hat. Auf Grund dieses Sachverhalts neige ich zu der Ansicht, daß es hier nicht der gallische Jurist, sondern der gallische Rhetor ist, der den Versuch macht, für sein Publikum etwas, was seiner Unterhaltung zu dienen verspricht, zusammenzustellen: ein bei der Art der Vorlage natürlich mißglückter Versuch ${ }^{2}$ ), wobei aber in Betracht kommt, daß es dem Verfasser eben wesentlich darum

1) Auf ein Verwandtschaftsverhältnis des Textes der Solmser Handsehrift und des Cod. Vatic. ist bereits Savigny-Zeitschrift (vgl. S. 981) S. $391^{4}$ hingewiesen. Mommsen, p. LVII, macht dann böchst wahrscheinlich, daß es das im Texte bezeichnete ist. - ") Der auch von dem Verfasser selbst nicht zu Ende geführt ist: er bricht mitten im Zuge ab (vgl. Savigny-Zeitschrift S. 390). 
zu tun gewesen sein wird, amüsante Kapitelüberschriften zu liefern, Überschriften, die natürlich, sozusagen, pro forma nicht ganz ohne Inhalt sein durften, wozu aber ein beliebiger, zunächst der erste Text des Titels Dienst tun konnte. ${ }^{1}$ ) Aus diesem Grunde mag sich auch der bescheidene Gebrauch, der von Theod. XVI gemacht ist, erklären, da dieses Buch sich nicht leicht für das lockere Spiel eignen mochte.

3. Es bleibt nun noch die Untersuchung des Auszugs, der an Bedeutung die bisher dargestellten bei weitem übertrifft und aus diesem Grunde auch eine besonders eingehende Erörterung erfordert. An Bedeutung hinsichtlich Umfang - der Auszug enthält von den 201 Gesetzen der Vorlage 53 - , hinsichtlich Wert und Einfluß. Es ist dies ein Auszug $^{2}$ ), der den wesentlichsten Teil einer Sammlung bildet, die in zwei Handschriften, dem Cod. Berol. Phillipps. 1741 Saec. X f. 179-189, von Reimser Ursprung, und dem Cod. Paris. 12445, (ehedem Sangerm. 366) Saec. IX/X f. 187b_202 ${ }^{\mathrm{b}}$ erhalten ist. ${ }^{3}$ ) Sie führt die Überschrift Incipit liber decimus sextus und besteht aus 14 durch fortlaufende Ziffern (I-XIII) und besondere Rubriken charakterisierten Abschnitten ${ }^{4}$ ), von

1) Auch die Beschränkung des Auszugs auf die ihm gerade vorliegende Hälfte von Theod. macht den Ernst der Leistung verdächtig. - 2) Vgl. hierzu N. A. XXIV, 349f. - 3) Die eingehendate Beschreibung der Berliner Handschrift bei Rose, Das Handschr.- Verzeichnis der Königl. Bibl. zu Berlin XII, 162f., der Pariser bei Haenel p. XXXVI ${ }^{390}$ (vgl. auch N. A. XXXV, 769 u. Mommsen p. LXXXVIII u. LXXXIX). Die Sammlung schliekt sich in beiden der Dionysio-Hadriana ( $\mathrm{gl}$. Maaßen, Geschichte d. Quellen u. d. Liter. d. kan. Rechts I, 442 sub N. 23 , u. S. 443 , sub N. 58) und angehängten kanonistischen Stücken

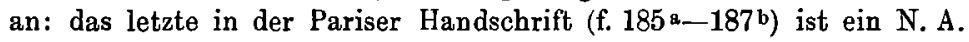
a. a. 0 . S. $770 \mathrm{f}$. beschriebener eherechtlicher Traktat, der weithin mit Text aus Hinkmar von Reims Gutachten über die Ehescheidung Lothars übereinstimmt. - ${ }^{4}$ ) Die vierzebnteilige Ordnung ist a. d. N. 2 a. O. S. $355^{3}$ (nach Cod. Phillipps.) und bei Mommsen p. XC u. $\mathrm{XCI}$ dritte Spalte, wo Cod. Phillipps. mit Y, Cod. Paris. mit D angegeben wird, verzeichnet. Es ergibt sich (aus der Beschreibung an der ersteren Stelle), daß der zweite Titel zwei Abschnitte (II u. IIJ) bildet, indem die im Breviar aufgenommenen Konstitutionen (die Breviarreihe) den zweiten, diejenigen, die Theod. allein angehören, nebst dem Texte (2) aus dem vierten Titel, den dritten Abschnitt bilden und die Rubrik des zweiten Titels einmal an der Spitze des zweiten Abschnitts, aber auch im dritten steht, hier jedoch nicht an der Spitze des Titels, sondern vor der 19. Konstitution. 
denen die ersten 10, in der Reihenfolge und mit den Rubriken der Vorlage, unter Wegfall des dritten De monachis, je einen Titel von Theod. repräsentieren, während über den elften Abschnitt, mit der Rubrik De episcopali iudicio, und die folgenden drei Abschnitte die ersten sieben Sirmondischen Konstitutionen, in der Reihenfolge der Sammlung, verteilt sind ${ }^{1}$ ): ihnen schließt sich dann ein Appendix an, der hier außer Betracht bleiben kann. ${ }^{2}$ ) Was den Bestand an Konstitutionen von Theod. anlangt ${ }^{3}$ ), so sind es teils die ins Breviar übergegangenen Texte, die vollzählig aufgenommen sind, teils eine Auswahl, wo dann von den im Breviar fehlenden Titeln (1. 4. 5.6. 11) lediglich eine solche Auswahl vorhanden ist. Breviar und sonst aus Theod. ausgezogener Text erscheint durchgängig in der Ordnung der Vorlage, andererseits, und zwar in der angegebenen Reihenfolge,

1) Während die ersten drei Konstitutionen den Abscbnitt XI ausmachen, bilden Sirm. 4 u. 7 jede einen Abschnitt für sich (XII v. XIIII) und Sirm. 5 u. 6 zusammen Abschnitt XIII). Die Abschnitte haben sämtlich Rubriken, von denen die von Abschnitt XIII (De his qui famis tempore sunt collecti) nur auf Sirm. 5 sich bezieht, andererseits vor Sirm. 6 steht. (Ich nehme an, daß schon die Vorlage zu Sirm. 6 keine Rubrik hatte, wie sie auch in Cod. Berol. Phillipps. 1745, der einzigen vollständigen Handschrift der Sirmondischen Konstitutionen, fehlt und durch eine übrigens hinter der Inskription aufgeführte Summe ersetzt ist.) Die Entlehnung der ersten sieben Konstitutionen gehört ausschließlich unserer Sammlung an. Hingegen findet sicb die Anfügung der ersten drei Konstitutionen an Theod. XVI, als dessen 11. Titel unter der Rubrik De episcopali iudicio, auch sonst, so in Cod. Epored. 35 (vgl. S. 92), stammt, wie ich glaube, aus sehr früber Zeit und ist unabhängig vom Breviar, ja wohl älter als dieses, wenn auch später auf einzelne Handschriften des Breviars (Paris. 9652 u. Leidens. Voss. quart. 119 [hier unter der Rubrik ' $X I$ in libro XVI Theodosii de episcopali iudicio ${ }^{\prime}$ ) übergegangen. Man vergleiche Mommsen p. CCCLXXVIII u. CCCLXXIX, und ed. Mommsen zu den bezüglichen Texten der Sirmondischen Sammlung. - 2) Es sind Texte aus dem Breviar, mit der Interpretation, und zwar teils Theod. $(9,1$ u. 1, 1), teils den Novellen Valentinians III. (35 [Br. 12]) und Marcian (1 [Br. 1]) entnommen. Vgl. N. A. a. d. S. $100^{2}$ a. O. S. 356 N. sub XIIII; N. A. XXXVI, $769^{1}$ sub N. 1; Mommsen p. LXXXVIII u. ed. P. Meyer p. LVIII u. LIX. - $\left.{ }^{3}\right)$ Ein Register der Texte bei Mommsen, p. XC u. XCI, dritte Spalte, worin die Breviartexte in viereckige Klammern eingeschlossen sind, und schon in N. A. a.d. S. $100^{2}$ a. O. S. $355^{3}$ (wo sub VIII hinzu-

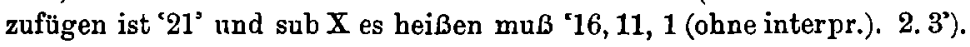


voneinander getrennt, so daß sich in den bezüglichen Titeln eine Breviarreihe und eine Theodosianusreihe unterscheiden läßt. ${ }^{1}$ ) Doch ist auch der Text der ersteren Reihe, der sich als solcher durch Beifügung der Interpretation kennzeichnet, nicht dem Breviar, sondern Theod. entlehnt; es ergibt sich dies nämlich aus dem Umstande, daß ein von dem Urheber der Sammlung befolgter Gebrauch auch hier beibehalten ist ${ }^{2}$ ): nämlich die in Theod. vorhandene Charakterisierung des konstituierenden Kaisers durch das Reflexivpronomen (Idem) auch dann zu übernehmen, wo diese Übernahme ein Fehler ist, weil die damit in Bezug genommene Konstitution ausgefallen ist. ${ }^{3}$ ) Es war dem Verfasser der

1) Nur im siebenten Abschnitt, der den Titel 'De Iudaeis caelicolis et Samaritanis' (8) repräsentiert, ist dies insofern nicht streng durchgeführt, als der Titel mit einem nicht dem Breviar angehörigen Gesetz (1) beginnt und erst dann die beiden Reihen (Breviarreihe [5. 7] und Theodosianusreibe $[6,16.27 .28])$ in der üblichen Folge sich anschließen. Die ausserhalb der Reihen stehende Konstitution könnte späterer Zusatz sein. $\left.-{ }^{2}\right)$ Der Sachverhalt, auf den a. d. S. $100^{2}$ a. O., S. 356, hingewiesen ist, kann an den Angaben mit Bezug auf Y u. D (vgl. S. $100^{4}$ ) zu den bezüglichen Inskriptionen der ed. Mommsen kontrolliert werden. $\mathrm{Er}$ findet sich so gut wie vollständig in dem zweiten Titel von Theod.. ln den folgenden Titeln ist in der Theodosianusreihe zuweilen das Idem durch einen Kaisernamen ersetzt (4, 2 [auch 2, 19] richtig; 6, 4 u. 10, 10 falsch), während in den Texten der Breviarreihe in zwei Fällen (8, 5 u. 7 [Br. 3, 1 u. 2]), wo das Breviar den Kaisernamen hat, das Idem von Theod. beibehalten ist, in einem dritten Falle (7, 3 [Br. 2, 1]) hingegen, mit dem Breviar, das Idem von Theod. durch den Kaisernamen ersetzt ist. Bezüglich der Abweichungen von der Regel kommt indessen in Betracht, dafs die Texte, in denen das Idem von Theod. dem Kaisernamen Platz gemacht hat, im Auszuge die erste Stelle des Titels einnehmen, was auch von der 19. Konstitution des zweiten Titels gilt, die, infolge eigentümlicher Anordnung, gleich hinter der Rubrik steht [ $\nabla$ gl. S. $\left.100^{4}\right]$ ): offenbar hat dieser Umstand dem Urheber der Sammlung, der Anstof nahm, die erste Konstitution mit Idem einzuführen, zur Änderung Anlaß gegeben. - ${ }^{3}$ ) Wenn hier aus dem Vorhandensein der Inskription von Theod. (Idem), statt der abweichenden des Breviars, gefolgert ist, dak auch der Text der Gesetze aus Theod. genommen wurde, so könnte man fragen, ob nicht aus dem Sachverhalt vielmehr der Schluf gezogen werden muß, daß die Konstitutionen, die ja auch die lediglich dem Breviar eigne Interpretation besitzen, daraus entlehnt sind uud nur eine nach Theod. umgestaltete Inskription haben. Die Textverhältnisse geben, soweit 
Sammlung, wie man daraus schließen muß, wenig daran gelegen, die Authentizität hinsichtlich der Personen der Gesetzgeber aufrechtzuerhalten: doch beweist der Fehler, der ja auch der Lex Romana Visigothorum nicht ganz fremd geblieben ist $^{1}$ ), mehr als die Minderwertigkeit der Leistung, den Mangel an historischem Interesse, der bei der vorauszusetzenden Bestimmung der Sammlung für praktische Zwecke nicht befremden kann. Das hier gezeichnete eigentümliche Verhältnis der Sammlung zum Breviarauszug drängt aber zunächst dazu, ihre Beziehung zu letzterem zu bestimmen und die hier gegebene Charakterisierung als eines Produkts, das sich die Ergänzung und Erweiterung der Lex Romana nicht zur Aufgabe gestellt hatte, zu rechtfertigen. In der Tat tritt sie auch in den beiden Handschriften nicht in dieser Gestalt zutage: es liegt eben nur die 'Liber decimus sextus' genannte Sammlung vor; enthält sie aber doch andererseits auch die Breviartexte von Theod. XVI und sind uns, wie wir sahen, auch Produkte dieser Art erhalten, so muß die Frage gestellt werden, ob ihr der Autor nicht diese Bestimmung zugedacht hatte. Ich glaube, diese Frage entschieden verneinen zu müssen. Sollte ihr Urheber in einer zur Ergänzung und Erweiterung des Gesetzbuchs bestimmten Sammlung Texte aufgenommen haben, die zu Rechtsinhalt, den das Breviar aufgenommen hat, in einem offensichtlichen Widerspruch stehen? Gewil ist nun aber letzteres der Fall. So erkennt die erste Sirmondische Konstitution, das Gesetz mit der Inskription 'Imp. Constantinus A. ad Ablabium P. P.' dem

ich sehe, keinen Entscheid über die Alternative. Es kommt mir indessen wahrscheinlicher vor, daß die vorhandene Inskribierung die ursprüngliche war, als daß sie erst an die Stelle der richtigen trat. Auch der Umstand, da $\beta$ die aus Theod. ins Breviar nur unvollständig übergegangene Konstitution aus dem Titel De apostatis (7, 3 [Br. 2, 1]) in der Sammlung im Umfang des Breviars erscheint (vgl. ed. Mommsen ad h. l. [p. 885]), spricht nicht entscheidend gegen unsere Annahme, da die Fassung der Inskription ergibt, daß in diesem besonderen Falle auf das Breviar zurückgegangen wurde (vgl. S. 102 2 ).

1) Vgl. Mommsen, p. CXXXVII sq. Er findet sich auch in den wenigen Fällen, wo dazu Gelegenheit war, im Solmser Auszug, aber auch im Cod. Epored., schließlich selbst bei der Hinzufügung von 9, 4 (vgl. S. $91^{2}$ ) (vgl. ed. Mommsen zu den bezüglichen Texten). 
Bischof Gerichtsbarkeit in bürgerlichen Sachen auch geger den Widerspruch einer Prozebpartei zu (Quicumque itaque litem habens, sive possessor sive petitor vel inter initia litis vel decursis temporum curriculis, sive cum negotium peroratur, sive cum iam coeperit promi sententia, iudicium elegerit sacrosanctae legis antistitis, ilico sine aliqua dubitatione, etiamsi alia pars refragatur, ad episcopum personae litigantium dirigantur): die in das Breviar übergegangene Novelle Valentinians III. (35 [Br. 12]) gewährt dagegen dem geistlichen Richter lediglich schiedsrichterliche Kompetenz. ${ }^{1}$ ) Aber nicht bloß aus der Sirmondischen Sammlung, sondern auch aus Theod. selbst sind Gesetze entlehnt, die dem Rechte des Breviars nicht entsprechen und zwar darum nicht, weil die Novellengesetzgebung ihnen derogierte und vom Kodifikator in das Gesetzbuch aufgenommen worden ist: so finden sich in der Sammlung gerade die durch die Novelle Valentinians III. (35 [Br. 12] § 4) verdrängten Gesetze (2,8.10.14 pr. \$1. 36 pr.), die von der Annahme ausgehen, daß der Kleriker Handel treiben darf, ferner eines $(2,20)$ der durch die Novelle Marcians (5 [Br. 5]) ausdrücklich aufgehobenen Gesetze, die gegen die zugunsten von Personen geistlichen Standes getroffenen Verfügungen von Frauen reagieren, schließlich die Normen über den Ausschlub der im Dienste städtischer Korporationen, insbesondere der Kurie tätigen Personen nebst Nachkommenschaft, aus dem Klerus (2, 3 und 19), auf die sich Novellen von Valentinian (35 [Br. 12] $\$ 3$ und 5)

1) Es heißt (pr.): de episcopali iudicio diversorum saepe causatio est: ne ulterius querella procedat, necesse est praesenti lege sanciri. Itaque cum inter clericos jurgium vertitur et ipsis litigatoribus convenit, habeat episcopus licentiam iudicandi, praeeunte tamen vinculo coupromissi. Quod et de laicis, si consentiant, auctoritas nostra permittit: aliter eos iudices esse non patimur, nisi voluntas iurgantium interposita, sicut dictum est, condicione praecedat, quoniam constat et episcopos forum legibus non habere. Daß die Abrede der Parteien, die Sache vor dem Bischof verhandeln zu lassen, kein (förmliches) Compromissum arbitri zu sein braucht, was noch Valentinian III. verlangte, hat dann Majorian verordnet, wie die Interpretation zur genannten Novelle Valentinians besagt (Lex ista de diversis rebus multa constituit; sed inprimis de clericis quod dictum est, ut nisi per compromissi vinculum iudicium episcopale non adeant, posteriore lege Maioriani abrogatum est). 
Westgot. u. kath. Auszüge d. 16. Buchs d. Theodosianus. 105

und Majorian (1 [Br. 1] § 7) beziehen (vgl. S. 69 f.). ${ }^{1}$ ) War somit die Sammlung nicht bestimmt, dem Breviar zu dienen, so könnte man meinen, daß sie wenigstens berufen war, nicht also das Breviar überhaupt, aber wohl den dem Breviar angehörigen Auszug von Theod. XVI zu erweitern und zu ergänzen bzw. mit diesem einen vollständigeren Auszug von Theod. XVI darzustellen. Hierfür könnte zu sprechen scheinen, daß ja eben die Überlieferung in den beiden Handschriften die Sammlung in Verbindung mit dem Breviarauszug von Theod. XVI präsentiert. Indessen bleiben sie in dieser Verbindung, wie wir sehen, doch immer getrennte Größen, wäbrend man bei der supponierten Absicht des Autors erwartet, daß er aus beiden Massen eine Einheit hergestellt haben würde. Auch erklärt sich von der Annahme aus, daß die Sammlung dem Breviarauszug von Theod. XVI dienen sollte, nicht leicht, weshalb dieser, wie wir annahmen, den Text aus Theod. genommen hat. Dagegen spricht aber auch, daß sie zu dem Ergebnis führen würde, die Sammlung diene doch nicht allein der Ergänzung und Erweiterung, sondern auch der Wiederholung von Rechtsinhalt des Breviarauszugs von Theod. XVI. Dieses Ergebnis ist aber durchaus unwahrscheinlich, zumal wenn sich die Wiederholung in so krasser Form darstellt, wie es hier der Fall wäre, wenn im Sinne des Urhebers Breviarauszug von Theod. XVI und Sammlung zusammengehörten. Eine Konstitution (2, 2 [Br. 1, 1]), die im Breviar vorkommt, erscheint nämlich sowohl in der Breviarwie in der Theodosianusreihe. ${ }^{2}$ ) Und wollte man hier auch annehmen, daß ein Versehen vorliegt, um die Tatsache, daß bei der erwähnten Annahme die Sammlung Wiederholungen des Breviarauszugs von Theod. XVI einschlösse, kommt man nicht herum; denn verschiedene der Sirmondischen entlehnte Konstitutionen unserer Sammlung treten auch im

1) Andererseits hätte es auch Wiederholungen mit dem Breviar gegeben: z. B. statuiert schon das Breviar in der Novelle Theodosius' II. (3 [Br. 3] $\$ 2$ u. 5 und Interpr.), was in die Sammlung aufgenommene Konstitutionen $(8,16$; Sirm. 6) aussprechen, die Unfähigkeit der Juden zur Bekleidung einer Militia. -- 2) Es heißt dann auch im Cod. Phillipps. zu dem Texte in der Theodosianusreihe (vgl. auch Mommsen ad h. l. [p. 835]): iteratur baec sententia. 
Breviarauszug auf (Sirm. $2=2,35[\mathrm{Br} .1,4]$; Sirm. $4=9,1$ $[$ Br. 4, 1] und 8, 5 [Br. 3, 1]), so daß auch hier eine Wiederholung in krassester Form vorliegen würde. Wiederholungen, die in Wiedergabe eines mit dem Breviarauszug sich deckenden Rechtsinhalts bestehen, finden sich noch häufiger; z. B. wenn die dritte Sirmondische Konstitution, indem sie geistliche Rechtssachen (quantum ad causas tamen ecclesiasticas pertinet, - quaestio quae ad Christianam pertineat sanctitatem) dem Bischof zuweist, nichts anderes sagt als was zwei in das Breviar aufgenommene Konstitutionen (2, 23 [Br. 1, 3]; $11,1[$ Br. 5, 1]) ausdrücken, wie auch eine in der Sammlung auftretende Konstitution von Theod. (7, 1), die mit der Apostasie in den Paganismus Versagung der Testierfähigkeit verbindet, in der Sache völlig mit einem Gesetz von 'Theod.XVI $(7,3$ [Br. 2, 1]) übereinstimmt, das in das Breviar aufgenommen ist. Man darf gegen die Schlüssigkeit unserer Argumentation nicht einwenden, daß dem Urheber der Sammlung bei seiner Auswahl die Übereinstimmung eines Textes mit dem Breviarauszug entgehen konnte: die Zahl der ihm angehörigen Texte ist hierzu nicht groß genug, und es wird sich zeigen, daß, als später die Sammlung wirklich mit dem Breviarauszug von Theod. XVI als Einheit betrachtet wurde, der Sachverhalt der Wiederholung von Konstitutionen des Breviarauszugs unter den Sirmondischen Konstitutionen als ein der Abhilfe bedürfender Umstand empfunden wurde (vgl. S. 116. 118. 119). Nach alledem erscheint mir so gut wie sicher, daß unsere Sammlung ein Produkt ist, das seiner Bestimmung nach weder mit dem Breviar überhaupt noch mit dem Breviarauszug von Theod. XVI etwas zu schaffen hatte, ein vom Breviar unabhängiges Produkt ist. Demnach wird aber auch die Verbindung mit dem Breviarauszug von Theod. XVI, in der es uns die Überlieferung aufweist, schwerlich ursprünglich und vielmehr erst später hergestellt sein, wofür doch auch sprechen mag, daß die Konstitutionen der Breviarreihe nach Theod. aufgenommen sind. ${ }^{1}$ ) Immerhin ist die Herstellung

1) Als man bei textkritischer Beschäftigung mit der Sammlung, die sich dabei des vollständigen Theod. bediente, auf den Einfall kam, den Breviarauszug daneben zu setzen, markierte man zu diesem Behufe, unter Beifügung der Interpretation, die dem Breviarauszug angehörigen 
der Verbindung doch auch alt, da sie von Hinkmar von Reims und der Epitome Parisiensis, an welcher letzteren Stelle, wie sich zeigen wird, die beiden Massen bereits als Einheit aufgefaßt werden, vorgefunden worden ist. Ich knüpfe an die Erörterung über das Verhältnis des Breviarauszugs von Theod. XVI zu unserer Sammlung eine Erwägung, die ich, bei der Sicherheit des obigen Ergebnisses, schwerlich als Widerlegung eines Bedenkens gegen das erzielte Resultat zu bezeichnen brauche. Es kommt nämlich in Betracht, daß, wenn unsere Sammlung nicht von vornherein zum Breviarauszug von Theod. XVI gehört hat, in ihr eine Konstitution mit einem Verbot der Hausgemeinschaft von Klerikern mit 'extraneae mulieres', wie sie der Breviarauszug aus Theod. XVI (2, 44 [Br. 1,6]) entlehnt, gefehlt haben würde, während man eine dem Klerus im Verkehr mit dem weiblichen Geschlechte Schranken auferlegende Satzung erwartet. Einer solchen begegnen wir gerade in Gestalt unserer Konstitution auf gallischem Boden - wie sich zeigen wird, dem Entstehungsgebiete der Sammlung - z. B. auf dem Konzil von Tours v. J. 567 (c. 21), in der Lex Baiuwariorum $(1,12)^{1}$ ) und Alamannorum $(39,1)$, bei Hinkmar von Reims. ${ }^{2}$ ) Es scheint mir indessen, daß unsere Sammlung im Punkte des Verhaltens des Klerus zu Personen weiblichen Geschlechts auf anderem Wege schließlich das gleiche, ja sogar ein weiteres Ziel erreicht. Aus dem Titel De haereticis (5) findet sich nämlich in die Sammlung ein Gesetz (53) aufgenommen, das dem Häretiker Jovinianus schwere Körperstrafe und nebst seinen Anhängern die Verbannung auferlegt und den künftigen Bekennern seiner Lehre noch strengere Ahndung in Aussicht stellt: seine Häresie bestand nun aber insbesondere in Leugnung der Verdienst-

Konstitutionen in dem benutzten Exemplar von Theod. und schrieb sie dann aus letzterem in die Sammluug hinein. Sowohl die Annahme der bezeichneten textkritischen Bemühungen als auch in Verbindung hiermit einer Verwertung von Breviarhandschriften hat an und für sich kaum etwas Anstößiges (vgl. etwa Mommsen p. XLV).

1) Hier in zugerichteter Gestalt, indem eine Gestattung des Gesetzes, Fortsetzung des Haushalts mit der Ehefrau bei Eintritt in den Klerus, nicht wiedergegeben ist. - ${ }^{2}$ ) Migne CXXV, 781 u. 1097. 
lichkeit der Askese des Mönchslebens und des Zölibats. ${ }^{1}$ ) Für die Aufnahme des Gesetzes weiß ich dann keine andere Erklärung zu finden ${ }^{2}$ ) als die, Kleriker damit zu treffen, die die Lehre Jovinians praktisch betätigten. ${ }^{3}$ ) Eine zweite in die Sammlung aufgenommene Satzung, die der Askese Vorschub leistet, ist das Personen geistlichen Standes auferlegte Gebot, sich des Besuchs der Wohnungen von Witwen und Waisen $\mathrm{zu}$ enthalten. ${ }^{4}$ )

4. Es soll nun noch in wenigen Strichen ein Bild von dem Inhalt unserer Sammlung gegeben werden. Es wird darin zunächst das katholische Glaubensbekenntnis verkündigt und den Kulten der Ketzer der Name der Kirche versagt

1) Realencykl. f. prot. Theol. ${ }^{3}$ IX, 398 f. kennzeichnet die Häresie als Widerspruch gegen das Mönchtum und als Vertretung der Gleichwertigkeit des ehelichen und jungfräulichen Standes, will sie indessen nicht gegen das Zölibat gerichtet sein lassen. Hergenröther, Handbuch d. allg. Kirchengesch. I, 398, bemerkt, daß Jovinian die Ehe überall empfahl, auch für Geistliche. - ${ }^{2}$ ) Jovinian stritt auch gegen die Lehre von der Virginität der Jungfrau Maria nach der Geburt Christi, und Ildefons ( $\dagger$ 667), Bischof von Toledo, bekämpfte ihn als Vertreter dieser Ketzerei. Doch sehe ich nicht ab, wie sich dieser Sachverhalt zur Erklärung verwerten läßt. Denn gewiß wäre es unzutreffend, wollte man meinen, der Urheber der Sammlung habe es dann mit der Konstitution auf die Bonosiaci oder Bonosianer abgesehen ( $\mathrm{ggl}$. S. $95^{3}$ ): die Bestreitung der Virginität nach der Geburt Christi durch Bonosus von Sardika, den Stifter der Sekte (?), geschah in einem ganz andern Sinn. Man vergleiche hierzu Realencykl. f. prot. Theol. ${ }^{3}$ XII, 312 u. 316; Hefele, a. a. O. II, 47. 49. - ') Der Inhalt der Häresie ist im Gesetze nicht angegeben, weshalb auch, obschon sein Erlaß (398 oder 412) in die Zeit Jovinians fallen wird, die Meinung aufkommen konnte (vgl. z. B. Haller, Jovinianus. Die Fragmente seiner Schriften S. 80), daß es sich auf einen unbekannten Häretiker, der nur den gleichen Namen führte, bezieht. Diejenigen, die es anging, werden aber wohl gewußt, bzw. sich vorgestellt haben, dafs der in dem Gesetze geächtete Jovinian und seine Anbänger die bekannte Lehre vertreten hatten, die eine überaus starke und in den Schriften des Ambrosius, Augustin und Hieronymus verewigte Anfechtung erfahren hatte. Daraus für die eigne Lebensführung die Nutzanwendung zu ziehen, durften sie dann um so weniger unterlassen, als es eine eigentliche Sekte der Jovinianer, soweit sich ermessen läfst, nur in unmittelbarem Anschluß an das Auftreten Jovinians gegeben haben wird. - ") Der Satz leitet die Konstitution $(2,20)$ ein, die sich gegen Zuwendungen ron Frauen an Personen geistlichen Standes wendet (vgl. S. 104). 
$(1,2$ u. $3 ; 11,2)$. Öffentliche Disputation, Peroration und Provokation mit Bezug auf die Religion ist bei Strafe verboten $(4,2)$. Hinsichtlich der Ketzer erfolgt Anerkennung der gegen sie gerichteten älteren Normen, der Satzungen der allgemeinen 'Sanktionen', ist die öffentliche Ausübung ibrer Gottesdienste mit Todesstrafe und Proskription bedroht und die Einziehung der Örtlichkeiten ihres Gottesdienstes und Übergabe ihrer Gotteshäuser an die katholischen Bischöfe angeordnet $(1,3 ; 5,4$. 51. 59. 63). Von einzelnen Häresien, die besonders hervorgehoben und verfolgt werden, soll noch weiter die Rede sein $(5,52$. 53. 59. 60; 6, 4; Sirm. 6). Was das Verhältnis zum Heidentum und Judentum anlangt, so ist Teilnahme am heidnischen Ritus, unter Androhung von Strafe gegen Judices, die das Verbot übertreten, untersagt, während die Apostasie zum Paganismus Verlust der Testamenti factio zur Folge hat $(5,63 ; 7,1 ; 10,10)$ : Heiden bzw. Juden sind von Militia honor administratoris vel iudicis bzw. Militia und von der Causidicina ausgeschlossen, und kein Christ soll ihnen als Sklave dienen $(8,16 ; 10,21$; Sirm. 6$)$. Beim Kaufe nichtjüdischer Sklaven durch einen Juden trifft den Käufer die Konfiskation und, falls der Sklave Christ ist, Proskription des ganzen Vermögens, während Beschneidung des gekauften Sklaven Kapitalstrafe des Juden und die Freiheit des Sklaven zur Folge hat (9, 2 u. 5; Sirm. 4). Christen, die zum Judentum abfallen, treffen die verdienten Strafen, während umgekehrt jüdische Proselyten gegenüber ihren früheren Glaubensgenossen, wie im allgemeinen gegen Tätlichkeiten, so im besonderen unter Androhung der Todesstrafe gegen Steinigung, ferner aber auch gegen erbrechtliche Verkürzung geschützt, ja erbrechtlich begünstigt sind $(8,1$ u. 28; Sirm. 4). Den Juden ist bei Kapitalstrafe verboten, Christinnen zu Konkubinen zu nehmen $(8,6)$. Wie es im allgemeinen bei den alten Verboten bleibt, so ist Errichtung neuer Synagogen verpönt, andererseits Wegnahme der bestehenden untersagt $(8,24)$. Die Kirchen werden in ihren Privilegien geschützt $(2,29$. 30. 34. 38. 40. 47; 11, 3; Sirm. 6). Demgemäß wird die Erbeinsetzungsfähigkeit der katbolischen Kirche anerkannt: hingegen sollen Kleriker nebst Nachkommenschaft sowie sonstige geistliche Personen wie 
sie bei Strafe die Häuser von Witwen und Waisen zu meiden haben, bei Gefahr der Konfiskation von den Frauen weder unter Lebenden noch letztwillig bedacht werden, sie seien denn ihre erbberechtigten Verwandten (2, 4 und 20). Der katholische Klerus wird im Besitze seiner Privilegien, wie im allgemeinen, so im besonderen im Punkte der Immunität von den munera geschützt $(2,1$. 2. 8. 10. 14 . 16. 29. 30. 34. 36. 38. 40. 47; 5, 1; Sirm. 6): die Gesetze (vgl. S. 70), die der Befreiung von der Grundsteuer ein Ende machten, fehlen. Inbegriffen sind Familie und Knechte, ferner die handeltreibenden Kleriker und die Custodes ecclesiarum vel sanctorum locorum $(2,8.14$ pr. $\$ 1$ u. 4 . 26. 36 pr.). Geschützt werden andererseits die Kurie und sonstige öffentliche Dienste, indem Kurialen nebst Nachkommenschaft und durch Besitz geeignete Personen, die sich jenen durch Eintritt in den Klerus entzogen haben, zu restituieren sind, es sei denn, daß sie bereits zehn Jahre dem Klerus angehören (2,3 u. 19). Mit Bezug auf Gerichtsbarkeit soll zunächst in geistlichen Sachen nicht der bürgerliche Richter, sondern das bischöfliche Gericht entscheiden, letzteres aber für Prozesse gegen Kleriker überhaupt, ja in bürgerlichen Streitsachen bei Anrufung seitens auch nur einer Partei und in jedem Stadium des Verfahrens ausschließlich zuständig sein $(2,47$; Sirm. 1. 3. 6.). Es wird die Folge unhaltbarer Anklage eines Klerikers vor dem bischöflichen Gericht und die prozessualische Vertretung der Kirchen geregelt (2,38 und 41). Als Beweis soll das Zeugnis eines einzigen Bischofs dienen (Sirm. 1). Ein Gesetz der Sirmondischen Sammlung (2), das den Sachverhalt des Betreibens der Wiedereinsetzung eines von seinen Mitbischöfen abgesetzten Bischofs betrifft, ist bereits bei Darstellung des Breviarauszugs, in dem es wiederkehrt $(1,4)$ beschrieben (vgl. S. 88). Abgesehen die schwersten Verbrecher sollen die Gefangenen zur Osterzeit freigelassen werden (Sirm. 7). Einem andern als dem kirchenrechtlichen, andererseits aber der Kirche doch nicht fremden Gebiete ${ }^{1}$ ) gehört schließlich der Satz an, daß der Herr bzw. Patron die zur

1) Vgl. im Allgemeinen God ofred us I 488 u. für Burgund Extrav. XX der Lex Burgundionum (MG. LL nat. Germ. II, 1, 119). 
Zeit der Hungersnot verkauften oder ausgesetzten Knechte von demjenigen, der sich ihrer angenommen hat, nur zum doppelten Preise und unter Ersatz der Auslagen vindizieren kann (Sirm. 5).

5. Will man die Sammlung, deren Inhalt hiermit gezeichnet worden ist, summarisch charakterisieren, so kann es dahin geschehen, daß wir ein Produkt vor uns haben, das alle Konsequenzen des ausgeprägten Katholizismus zieht, daher der Ketzerei mit Entschiedenheit entgegentritt, auch wohl, im Verhältnis zu dem Breviarauszug, den Antisemitismus steigert, gegen den Paganismus indessen eine gewisse Nachsicht bewahrt. Man kann aber die Sammlung gleichzeitig als ein zweckentsprechendes Produkt charakterisieren, insbesondere nach ihren Erfolgen: denn diese sind in der Tat sehr bedeutend gewesen. Zunächst ist ganz sicher, daß Hinkmar von Reims $\left.(\dagger 882)^{1}\right)$ Theod. XVI, welche Quelle von ihm stark verwertet worden ist, nach unserer Sammlung benutzt hat, und zwar der Sammlung bereits in der Gestalt der Verknüpfung mit dem Breviarauszug, in der sie in Cod. Berol. Phillipps. Saec. X, selbst Reimser Ursprungs (vgl. S. 100) ${ }^{2}$ ), und in Cod. Paris. (ehedem Sangerm.) Saec. IX/X begegnet. ${ }^{3}$ ). Hinkmar war eine der hervorragendsten und einflußreichstenPersönlichkeiten seines Zeitalters und sein Einfluß zeigt sich auch im Punkte der Benutzung unserer Sammlung, insofern daraus Texte in die Kanonensammlungen der folgenden Jahrhunderte übergegangen sind ${ }^{4}$ ):

1) Als Werk Hinkmars können auch die Akten des ersten Konzils von Doury v. J. 871 gelten (Mansi XVI, 569 seq.). Ein im Breviar fehlender Text $(2,41)$ wird gewiß auf die Sammlung zurückgehen, wie Spuren selbst auf Benutzung des Appendix weisen (vgl. N. A. XXXV, 774²). 2) Man mag annehmen, daß Cod. Phillipps. auf die von Hinkmar benutzte Handschrift zurückgeht, bez. daB bei der Anfertigung ersterer der Sachverhalt der Benutzung der Sammlung durch den Erzbischof eine Rolle gespielt hat. - ${ }^{3}$ ) Vgl. N. A. XXIV, 349 seq. u. zustimmend Mommsen, p. LXXXIX u. ed. P. Meyer p. LIX. Zu den an erster Stelle aufgeführten: Momenten ( $v$ gl. auch $u$. a. XXXV, $770^{\circ}$ ) fügt $M$ ommsen a. a. O. hinzu, daB Hinkmar auch die in unsere Sammlung aufgenommene dritte Sirmondische Konstitution benutzt und charakteristische Lesarten des Textes der Sammlung aufweist. - ${ }^{\text {) }}$ ) So in die einflußreiche Kanonensammlung des Anselm v. Lucca (vgl. Geschichte der Quellen I, 364f.). Unmittelbar stammen die Texte Hinkmars hier aus einer Collectio LXXIV titulorum, die weithin für Kanonensammlungen die direkte Quelle der aus unserer Sammlung geschöpften Hinkmariana ist. Hierüber orientiert v. Wretschko bei Mommsen p. CCCLVII u. CCCXLVIII. 
Theod. selbst ist vom Schriftsteller weder sonst ${ }^{1}$ ), noch mit Bezug auf das 16. Buch benutzt. ${ }^{2}$ ) Sagt Hinkmar bei Zitierung von Texten der Sammlung, daß sie aus dem 'sextus decimus liber" ('liber decimus sextus legis Romanae', 'decimus sextus liber Theodosianae legis'), aus der Zahl derjenigen Leges stammen, die, neben den kanonischen Gesetzen, den Kanonen der Konzilien und Dekreten der Päpste, die Kirche beherrschen ${ }^{3}$ ), eine Charakterisierung, die er mit den Justinianischen Novellen, in Gestalt der Epito me Juliani, teilt ${ }^{4}$ ), so kann recht gut in seinem Sinne der 'sextus decimus liber' gerade unsere Sammlung sein. ${ }^{5}$ )

1) Allerdings findet sich bei Hinkmar (Migne CXXVI, 403) ein Theod. angehöriger Text, der in der Sammlung nicht begegnet: er wird mit 'in libro sexto titulo decimo nono' eingeführt, gehört jedoch dem vierten Buche und siebzehnten Titel $(4,17,1)$ an. In Wahrheit ist er indessen nit dem ganzen Passus, in dem er sich findet, nicht Theod. entnommen, sondern geht auf den Codex Justinianus zurück, wird aber direkt dem Kommonitorium Gregors I. an den Defensor Johannes, einer von Hinkmar viel benutzten Quelle, entlehnt (MG. Epistolae II, 414 seq. [13, 50]): auch unsere heutige Überlieferung des Kommonitorium weist, zum Teil, die (verkehrte) Zitierung (statt 7, 44, 3) auf (vgl. MG. ad. h. l. [p. 418]). Mommsen a. a. O. (vgl. auch ed. Mommsen ad. 4, 17, 1 [p. 198]) läßt den Text aus Theod. herstammen, indessen direkt dem Appendix des Breviars, wo er sich aufgenommen findet, entlehnt sein; an einer anderen Stelle (Coll. libr. iuris anteiust. III, 112') erkennt er indessen selbst das Richtige. $\left.-{ }^{2}\right)$ Vier Texte von Theod. XVI gehen auf die Quesnelsche Sammlung zurück (vgl. N. A. a.d. S. $100^{2}$ a. O. S. 350 u. 351 u. Mommsen p. LXXXIX). - s) Es handelt sich um die folgenden Stellen. Qualiter autem ordinati ministros sibi suppositos regere debeant, sacri canones et decreta sedis Romanae pontificum, sed et sextus decimus liber legum, quibus una cum sacris canonibus sancta moderatur ecclesia, patenter ostendunt (Migne $\operatorname{LXX} \nabla, 1010$ ). Quod et leges, quibus cum sacris canonibus sancta moderatur ecclesia, ita in decimo sexto libro Theodosianae legis confirmant (a. a. O. p. 1045 [ vgl. auch p. 1039]). Dem Sinn nach ist das gleiche in folgendem Texte gesagt: lege librum XVI legis Romanae, lege decreta Damasi.., et invenies, quantum profuerit atque prosit legum severitas, non solum ecclesiasticae lenitati, verum totius Christianitatis aptandae pari et colendae tranquillitati (a. a. O. CXXVI, 158). - 4) Vgl. z. B. proponam tibi legalem sententiam Iustiniani catholici imperatoris, quam probat et servat ecclesia catholica (Migne CXXVI, 411); lex Instiniani catholici imperatoris, quam probat et servat ecclesia catholica (a. a. 0. p. 573); leges quibus debitae observationis reverentiam sancta ecclesia exhibet in constitutione ... (a. a. 0. p. 489) usw. - s) Die Sammlung ist in der Überlieferung als 'liber $X \nabla I$ ' überschrieben. Hinkmar schöpft ja aus ihr so gut wie alles, allerdings auch aus der 
Beherrscht wird die Kirche durch die Gesetze, die sie im kirchlichen Forum anwendet ${ }^{1}$ ), wie dies ja von einem guten Teil unserer Sammlung ${ }^{2}$ ) angenommen werden kann. ${ }^{3}$ ) Hinkmar bedient sich der Konstitutionen unserer Sammlung indessen auch da, wo ihre Anwendung vor dem geistlichen Forum nicht in Betracht kommen konnte, die Kirche aber ihnen Billigung und Gunst zuteil werden läßt. ${ }^{4}$ ) Man sieht dann,

Quesnelschen Sammlung (vgl. S. 112²), die indessen anders zitiert wird (in XVI libro Theodosiano [vgl. Migne CXXV 401 u. 402]). Bemerkenswert ist aber auch der folgende Satz des Schriftstellers (CXXV, 1039): scio sapientiam vestram ex his, quae de decimo sexto libro Theodosianae legis sunt posita, debere comprehendere plura. Wovon hier gesagt ist, $\mathrm{da} B$ es vorstehend dem 'decimus sextus liber Theodosianae legis' entnommen wurde $(2,8,16.26 .29 .30 .31 .34)$, ist nicht allein in unserer Sammlung zu finden, sondern überwiegend die Reihenfolge der Sammlung selbst (2, 26. 29. 30. 31. 34).

1) Mögen sie durch eine kirchliche Rechtsquelle rezipiert sein oder nicht, erstere z. B. die in das Kommonitorium Gregors I. aufgenommenen Texte Justinianischen Rechts, die dadurch kanonisch geworden sind (vgl. Migne CXXV 652 u. 1088 und CXXVI 403). - 2) Wozu bei Hinknuar auch Tezte von Theod. gehören, die auferhalb Theod. XVI sich befinden und ihm durch das Breviar bekannt sind. Hierzu gehören die auf das gemeine Strafverfahren bezüglichen Texte, auf die übrigens gleichfalls eine kirchliche Quelle (Concil. Tolet. VI [c. 11]) hingewiesen bat (Migne CXXV 389. 1094. 1095; CXXVI 442). Aus diesem Grunde hat gerade aus dem Breviar das neunte Buch von Theod, insbesondere der erste Titel 'De accusationibus et inscriptionibus', im früheren Mittelalter eine überaus große Beachtung gefunden, wovon v. Wretschk os Zusammenstellung bei Mommsen p. CCCLXI seq., ein Bild gibt. Aus dem ersten Titel ist ja auch Verschiedenes in den Appendix unserer Sammlung (vgl. S.101 2) ja selbst in den Solmser Auszug übergegangen. - ${ }^{3}$ ) Hierzu gehören die Satzungen mit Bezug auf den S.112 ${ }^{\circ}$ erwähnten Sachverhalt 'qualiter... ordinati ministros sibi suppositos regere debeant', hinsichtlich des Verbots der Aufnahme fremder Frauen durch Kleriker (Migne CXXV 781 u. 1097), hinsichtlich des Gerichtsstands der Geistlichen (a. a. 0. p. 1045 - 1056), auch mit Bezug auf den Sachverhalt der Konfiskation kirchlichen Besitzes durch Laienurteil (a. a. O.p. 1038 u. 1044). Verschiedene der von Hinkmar verwendeten Texte von Theod. XVI, die übrigens mehrfach für die von ihm vertretene Ansicht geringe oder gar keine Beweiskraft haben, gehören dem Breviarauszug von Theod. XVI an, den ja Hinkmar in seiner Vorlage mit der Sammlung verbunden fand. - 4) Hierzu gehören die Gesetze, die sich gegen das Verbrechen der Häresie wenden, wovon Hinkmar sagt (Migne CXXV 403): his Christianis Christianorum imperatorum legibus catholica favet (faveat) mater ecclesia. 
welcher Art die praktische Verwertung ist, welches die praktischen Zwecke sind, denen die Sammlung diente, und für die sie vermutlich auch bestimmt gewesen ist. Sind hiermit die Verwendungsweisen, die sich sonst mit Bezug auf die Texte des römischen Rechts bei Hinkmar finden, schwerlich erschöpft ${ }^{1}$ ), so mag gerade mit Bezug auf Theod. XVI von dem Erzbischof von Reims lediglich zu den bezeich-. neten Zwecken Gebrauch gemacht worden sein. Wohl aber liegt eine andere Verwendungsweise, deren Charakterisierung an dieser Stelle sich erübrigt, vor, wenn wir der Benutzung unserer Sammlung in den großen Kapitularien- und Dekretalenfälschungen des 9. Jahrhunderts begegnen. Eine literarische Erscheinung, die neben Hinkmar den zweiten Rang weder aus dem Gesichtspunkt des Alters, das vielmehr ein um Jahrzehnte höheres sein mag, noch im Punkte des Einflusses verdient, und nur um deswillen erst hier zur Sprache kommt, weil der Nachweis des bezeichneten Verhältnisses nicht mit der gleichen Sicherheit, wie bei Hinkmar geführt werden kann. Die Annahme ${ }^{2}$ ), daß insbesondere Benedikt Levita ${ }^{3}$ ) seine auf Theod. XVI zurückgehenden Texte aus unserer Sammlung, etwa gleichfalls in der Gestalt einer Verknüpfung mit dem Breviarauszug dieses Buchs, entlehnte, läßt sich nicht schon auf den Umstand gründen, daß er in einem gefälschten Kapitular (II, 366) mit den Worten 'ex sexto decimo Theodosii imperatoris libro, capitulo videlicet XI., ad interrogata Ablavii ducis ${ }^{34}$ ) Text der ersten Sirmondischen Konstitution einführt, da ja dieses Gesetz nicht bloß in unserer Sammlung, sondern auch im Cod. Epored. (vgl. S. 92), aber auch sonst (vgl. S. 101 ${ }^{1}$ ), Theod. XVI als elfter Titel angehängt wurde. Hingegen

1) Zuweilen dienen dem Schriftsteller die den römischen Quellen entlehnten Texte lediglich als Parallele, oder als Formulierung eines sozusagen naturrechtlichen Satzes oder ihre Verwendung trägt geradezu den Charakter eines Witzes. - ${ }^{2}$ ) Zu ihr neigt auch ed. Meyer p. LIX. - ${ }^{3}$ ) Die Entscheidung, ob Pseudo-Isidors Verwertung von Theod. XVI (vgl. v. Wretschko bei Mommsen p. CCCXXXIX u. CCCXXXVIII) auf die Sammlung, etwa den Breviarauszug eingeschlossen, zurückgeht, wird von Entscheidung der Frage, wie es sich mit Benedikt Levita verhält, abhängen. - ${ }^{4}$ ) Vgl. Seckel, N. A. $\mathrm{XXXV}, 477$. 
kommt in Betracht, daß bei Benedikt Levita keine Konstitution von Theod. XVI begegnet ${ }^{1}$ ), die nicht unserer Sammlung oder wenigstens dem Breviarauszug angehört, und in der Reihenfolge der von dem Fälscher benutzten Texte ${ }^{2}$ ), ingleichen in charakteristischen Lesarten, Spuren ihrer Benutzung zu begegnen scheinen. ${ }^{3}$ ) Nach den Schriften Hinkmars und den großen Fälschungen ist dann noch die nach der Handschrift, in der sie uns erhalten ist, einem Pariser Kodex ${ }^{4}$ ), Epitome Parisiensis genannte Bearbeitung des Breviars zu nennen. Sie wird die ersteren an Alter übertreffen: es sind Gründe vorhanden, die ihre Abfassung vor dem Beginn des 9. Jahrhunderts, etwa in dem Zeitraum zwischen derMitte des siebenten und der bezeichneten Grenze annehmen lassen. ${ }^{5}$ ) Die Sammlung liegt uns indessen hier mit veränderter Zweck-

1) Ein Register der auf Theod. XVI zurückgehenden Texte der beiden ersten Bücher, nach ihrem Vorkommen im Breviarauszug und außerhalb des Auszugs geordnet, gibt Seckel, N. A. XXXI, 135 u. XXXV, 535 u. 538. Die dem Breviar fremden Texte von Theod. XVI bezeichnet $\mathrm{Seckel}$ als einem vermehrten Breviar (Brev. auct.) entlehnt: der Bezeichnung 'Cod. Theod. (canonice comptus?)' (a. a. O. XXXI, 135) liegt die Ansicht Seckels zugrunde, dafs sich Benedikt Levita an den betreffenden Stellen nicht der Fassung von Theod. XVI selbst, sondern einer klerikalen Bearbeitung der Art, wie sie mit Bezug anf die Epitome Iuliani erbalten geblieben ist (Summa de ordine ecclesiastico) bedient haben mag (vgl. a. a. $0 . X X X V, 535$ sub Dd u. e). Ein Verzeichnis der Texte aller drei Bücher von v. Wretschko bei Mommsen p. CCCXXXIV sq.). ${ }^{2}$ ) Hinsichtlich II 113-117 bemerkt Seckel, a. a. 0 . $\mathrm{XXXV}, 364$, daß sie eine Reihe bilden und zwar gemessen nicht sowohl am echten Theod., als vielmehr am Brev. auct., wie es insbesondere in den beiden Handschriften unserer Sammlung vorliegt (vgl. anch a. a. O. S. 478). Es läbt sich auch auf III 421. 422.438 hinweisen, die, auf 2,47 u. 41 zurückgehend, in der Sammlung, nur in umgekehrter Folge, einer bei Benedikt Levitas Entlehnungen ganz üblichen Erscheinung, auftreten. - ${ }^{3}$ ) Es läßt sich auf Grund der Angaben in ed. Mommsen weithin zeigen, daß zwischen dem Texte unserer Sammlung und von Benedikt Levita eine nahe Verwandschaft besteht (vgl. Seckel, a. a. O. XXXI 114 u. XXXIIII 362. 364; XXXV 477). Der Umstand, daß vereinzelt Abweichung, bzw. größere Verwandtschaft mit Cod. Epored. zutage tritt (vgl. a. a. O. XXXIV $363^{3}$, u. XXXV 478) beweist nur, daf Benedikt Levita die Sammlung nicht gerade aus Handschriften, die sich völlig mit unserer Überlieferung decken, schöpfte. 4) Vgl. Mommsen, p. LXXXIX. XC. CIsq. - ") Vgl. Geschichte der Quellen I 230. 
bestimmung und in völlig verändertem Gewande vor. Aus der Nebeneinandersetzung von Sammlung und Auszug ist nunmehr eine Einheit geworden und diese Einheit dient hier dem Zwecke, Theod. XVI des Breviars zu repräsentieren. Während dann im allgemeinen diese Repräsentation Ordnung und Bestand der Vorlage, Breviarauszug und Sammlung, wiedergibt ${ }^{1}$ ), von bedeutungslosen Abweichungen abgesehen ${ }^{2}$ ), hat der Epitomator immerhin nicht unterlassen, der veränderten Bestimmung Rechnung zu tragen, indem er gelegentlich, wo eine Sirmondische Konstitution schon im Breviarauszug vertreten war, durch Streichung an der ersten Stelle Abhilfe schaffte. ${ }^{3}$ ) Was aber die Gestalt anlangt, in der das Produkt erscheint ${ }^{4}$, so ist es nicht nur nicht die originale, ja im Grunde auch nicht eine epitomierte im allgemeinen und in der Art

1) Vgl. Mommsen p. XC u. XCI, zweite Spalte. - 2) Hierzu gehört das Fehlen des Titels De haereticis (5): nach der Bezifferung der Abschnitte ist er jedoch in der Vorlage vorhanden gewesen (als sechster Titel). Ferner erscheint nur die erste der Sirmondischen Konstitutionen unter der Rubrik 'De episcopali indicio'. Hierauf folgt das 'Explic. de corpore Theudosiani codicis libri XVI' und daran schließen sich ohne Verteilung in Abschnitte die im Texte genannten Konstitutionen an. Hingegen darf man schwerlich sagen, zu welcher Annahme der Abdruck bei Mommsen p. XCI verleiten kőnnte, daß die Sirmondischen Konstitutionen, von der ersten abgesehen, andere Rubriken gehabt haben: die bei Mommsen abgedruckten Worte sollten schwerlich als Rubriken dienen, die vielmehr nicht aufgenommen wurden, sondern die ersten Textworte der Summe darstellen. - 3) Mommsen p. XCI, gibt (neben 1) die Konstitutionen 2. 5. 3 als die aufgenommenen an: in Wahrheit sind es 2. 5. 7, so daß von den sieben der Sammlung 3. 4. 6 fehlen. Die vierte wiederholt 8,5 (Br. $3,1)$ u. 9, 1 (Br. 4, 1) und wird darum gestrichen worden sein. Auf die Streichung von Sirm. 6, die eine ähnliche Ursache hat, komme ich zurïck (vgl. S. 118). Entsprechend mag sich auch das Fehlen vereinzelter Konstitutionen von Theod. damit erklären, daß das Breviar, dem nun die beiden Massen, Breviarauszug von Theod. XVI und Sammlung, als Einheit einverleibt waren, den gleichen Rechtsinhalt an anderer Stelle enthält: so der Ausfall von 7, 1 wegen 7, 3 (Br. 2, 1) und von 8, 16 u. 27 wegen Nov. Theod. II 3 (Br. 3) \& 2. 3. 5. Anderes mag durch einen Zufall ausgefallen sein $(2,36 ; 10,10 ; 11,2)$. (Umgekehrt enthält die Epitome die Summe einer Konstitution [2, 9], die in der Sammlung bzw. dem Breviarauszug von Theod. XVI fehlt). - 4) Die Epitome Parisiensis ist von Haenel p. $17 \mathrm{sq}$. herausgegeben. Die Texte von Theod. XVI beginnen p. 244. 
der Epitome Parisiensis insbesondere: was uns von den Konstitutionen gegeben wird, trägt weithin Summen, - ja zuweilen Rubrikencharakter; es könnte sein, daß der Epitomator hiermit eine von ihm vorgefundene Glosse zu der Sammlung wiedergibt. ${ }^{1}$ ) Der Erscheinung, unsere Sammlung mit dem Breviarauszug zu einer Einheit zu verknüpfen und im Breviar Theod. XVI vertreten zu lassen, begegnen wir nicht bloß in der Epitome Parisiensis ${ }^{2}$ ); sie findet sich vielmehr auch in der merkwürdigen, von Wilhelm v. Malmesbury zwischen 1125 und 1137 geschriebenen Oxforder Handschrift, worin der Schreiber und Autor seinem Werk über Römische Geschichte auch das Breviar einverleibt hat. ${ }^{3}$ ) Der Autor bewährt die Freiheit bzw. Willkür, mit der er überhaupt seine vermutlich gallische ${ }^{4}$ ) Vorlage behandelt ${ }^{5}$ ), auch in dem letzten Buch von Theod., das hier übrigens das fünfzehnte ist, während er die Teilung in XIV Abschnitte beibehält. ${ }^{6}$ ) Seine Änderungen bestehen insbesondere hierin, daß er die $\mathrm{Ab}$ schnitte bzw. 'Titel versetzt und die von den Häretikern und der Ketzerei der Wiedertaufe handelnden Titel (5 und 6), nach Art der Ketzereien, über nicht weniger als 5 Abschnitte verteilt (4 de hereticis; 5 De Donatistis; 6 De Joviniano; 7 De Eunominianis et ceteris; 8 De Manichaeis) ${ }^{7}$ ),

1) Ond zwar zu der Sammlung allein; denn die Bearbeitung des Breviarauszugs von Theod. XVI scheint mir überwiegend anderer Art als die der Texte unserer Sammlung und mehr im Stile dieser Epitome zu sein. Der Gegenstand erfordert indessen nähere Untersuchung, wobei es sich auch um das Verhältnis der Summen von Theod. XVI zu den gleichartigen Texten handelt, die den Inhalt von in das Breviar eingeschalteten Konstitutionen anderer Bücher von Theod. wiedergeben (vgl. Mommsen, p. XC). Diese und jene Summen könnten auf alte Scholien von Theod. zurückgehen (vgl. Geschichte der Quellen I 231). $\left.-{ }^{2}\right)$ In Cod. Ambros. C 29 inf. Saec. XI, einer Breviarhandschrift, bezeugt das Rubrikenregister von Theod. XVI, daß einzelnes aus der Sammlung (aus dem vierten Titel, Sirm. 5 u. 7) übergegangen war (vgl. M ommsen p. LXXXV u. CCCLXXIX): der Text selbst ist nicht erhalten. - ${ }^{\text {s) }}$ Vgl. Mommsen p. LXV sq., CXXXII, CXLI. - ${ }^{4}$ ) Vgl. ed. Meyer p. XLVILI. - ${ }^{5}$ ) Vgl. Mommsen p. LXVI, u. Haenel p. XXX u. XXXI. Es verlohnt sich deshalb nicht, in dieser Verbindung den Gegenstand zu erschöpfen. - ${ }^{6}$ ) Ordnung und Bestand bei Mommsen p. XC u. XCI vierte Spalte. Die Handschrift ist hier und in ed. Mommsen mit dem Buchstaben $O$ bezeichnet. - T) Wie er auch im zweiten Buch 
und daß er von den Sirmondischen Konstitutionen nur diejenigen, die nicht auch im Breviar stehen, zum Schluß (5 und 7) oder im jew eiligen Titel von Theod. aufnimmt (1 und 3), die im Breviar wiederkehrenden ${ }^{1}$ ) aber streicht. ${ }^{2}$ )

6. Ich schließe, mich der im vorstehenden gewonnenen Daten bedienend, mit dem Versuch einer Feststellung der Entstehungsverhältnisse unserer Sammlung. Mir erscheint es dann mehr als wahrscheinlich, daß sie in Gallien ihren Ursprung hat. Hier benutzten sie Hinkmar, Benedikt Levita und die Epitome Parisiensis, insbesondere die letztere, wie man annehmen kann, zu einer von ihrer Entstehung nicht gar zu weit abliegenden Zeit: hier ist aber auch die Heimat der beiden Handschriften zu suchen, die sie uns überliefert haben. ${ }^{3}$ ) Die Annahme gallischer Entstehung wird aber noch besonders durch den folgenden Sachverhalt unterstützt. Ich habe oben (S. 105) die Tatsache des Vorkommens einer und derselben Konstitution unter den Sirmondischen Texten unserer Sammlung und im Breviarauszug gegen die Annahme ihrer ursprünglichen Zusammengehörigkeit verwendet. Nun enthält aber unsere Sammlung selbst den gleichen Gesetzestext vom Jahre 425, einmal als sechste Sirmondische Konstitution und sodann im zweiten Titel von Theod. XVI zum Schluß (47). Das Auffallende dieses Umstandes ist auch von den Benutzern der Sammlung empfunden worden: in der Epitome Parisiensis fehlt die sechste Sirmondische Konstitution,

von Theod. den ersten Titel in drei verteilt (und die Titel versetzt) (vgl. ed. Mommsen p. 8).

1) Auf Sirm. 6 komme ich noch zu sprechen (vgl.S. 119). - ${ }^{2}$ ) Gestrichen ist die vierte Konstitution, die von den Juden bandelt: sie kehrt nämlich im Breviar (8,5 [Br. 3, 1] u. 9, 1 [Br. 4, 1]; letztere ist indessen hier ausgefallen) wieder. Ebenso ist die zweite Konstitution, die im Breviar (2, 35 [Br. 1, 4]) wiederholt ist, gestrichen bzw. nur für die Interpolierung des Breviartextes zur Geltung gekommen. 3) Cod. Phillipps. ist Reimser Ursprungs (vgl. S. 100), worauf ed. P. Meyer, p. LIX, die Annahme gründen mag, daß die Sammlung selbst aus Reims stammt. Cod. Paris. (ehedem Sangerm.) Saec. IX/X, dessen Abfassung jedenfalls nicht lange nach Hinkmar fällt, muß schon wegen des Verhältnisses, in dem einzelne Stücke zu den Schriften Hinkmars stehen (vgl. N. A. XXXV 710), für gallisch gelten. Beide Handschriften vermerken Lesarten aus einer Handschrift von St. Denis (vgl. Momms en p. XLV, CV). 
Westgot. u. kath. Auszüge d. 16. Buchs d. Theodosianus. 119

umgekehrt im Oxforder Kodex die Stelle aus dem zweiten Titel, wie ja die von ihm beliebte Anfügung der Sirmondischen Konstitution hinter den zweiten Titel die Beibehaltung des Gesetzes zum Schluß des zweiten Titels besonders auffallend gemacht haben würde. ${ }^{1}$ ) Der Redaktor unserer Sammlung muß dann einen Grund, man kann sagen, einen zwingenden Grund gehabt haben, wenn er die Stelle zweimal aufnahm, dieser Grund aber liegt nicht allzufern. Es kommt nämlich in Betracht, daß, obschon der Text des zweiten Titels, von unbedeutenden und für den Sinn unerheblichen Abweichungen abgesehen, in der Fassung des Gesetzes der Sirmondischen Sammlung wiederkehrt, letztere doch auch ihr Besonderes hat, nämlich eine Inskription, die es an den Praefectus praetorio Galliarum adressiert sein läßt ${ }^{2}$ ) und einen sich an das Gemeinsame anschließenden weiteren Text. Er richtet sich insbesondere gegen die dem Dogma Pelagianum et Caelestianum zugefallenen Bischöfe, verordnet ihre Belangung durch Patroclus, offenbar den Primas von Arles dieses Namens, der ein Jahr später bei der Belagerung von Arles durch die Goten starb ${ }^{3}$ ), und für den Fall ihrer Resistenz, ihre Vertreibung aus den Gallischen Regionen (Gallicanae regiones), wie aber weiter die Entfernung der Manichäer, aller Häretiker, Schismatiker und Mathematici, ja jeder den Katholiken feindlichen Sekte aus den Städten befohlen wird.4) Ich erblicke dann den Grund der Wiederholung des Gesetzes gerade in diesem Rechtsinhalt, indem der Urheber, der damit die Entstehung der Sammlung auf gallischem Boden bezeigt, den gallischen Lesern und Benutzern der Sammlung, für die sie zunächst bestimmt war, das gesetzliche Gebot einer Verfolgung der Ketzer gleichsam ad hominem vordemonstrieren wollte: ein anderer Grund ist, wie mir scheint, unerfindlich ${ }^{5}$ ), zumal da Theod. XVI dem

1) Vgl. Mommsen, p. XC u. XCI, zweite und vierte Spalte. - ${ }^{2}$ ) Sie lautet: Impp. Theodosius A. et Valentinianus Caesar Amatio V. I. Praefecto Praetorio Galliarum. Hingegen ist nach der Inskription in Theod. das Gesetz 'Basso comiti rerum privatarum' adressiert. Auch das Datum variiert (an ersterer Stelle d.9. Juli [6. August], an der zweiten d. 8. Oktober). - ${ }^{3}$ ) Vgl. Gams, Series episcoporum p. 493. - ${ }^{4}$ ) Der mit den Manichäern einsetzende Teil ist auch in Theod. XVI übergegangen (5, 62 u. 64). Vgl. Mommsen p. CCCI. - s) Die Sirmondische Fassung des Gesetzes enthält allerdings zum Schluß auch Sonstiges, was sich 
Sammler hierzu keine sonstige Gelegenheit bot (illud memorabile, per Gallias nullam haeresin hoc Codice memorari [vgl. S. $77^{1}$ ]). Ist also Gallien die Heimat der Sammlung, so kann man weiter gehen und annehmen, daß sie in Gallien inmitten eines katholischen Staatswesens entstanden ist: daß ihre Abfassung in die Zeit und auf den Boden der arianischen Königreiche, insbesondere des tolosanischen Reichs fällt, ist darum unwahrscheinlich, weil ein Produkt von so entschieden katholischer und darum auch gegen die Arianer gerichteter Tendenz (vgl. S. 122) schwerlich unter der Herrschaft arianischer Könige hervorgegangen sein wird. Ergibt sich hieraus als Ausgangspunkt für die Entstehungszeit der Sammlung kaum ein weiteres Datum, als es schon die Benutzung von Theod. darbietet, da Gallien nicht erst unter den Franken bzw. Burgunden katholische Staatswesen besaß, vielmehr schon das weströmische Reich ein solches gewesen ist, so wird man den Endpunkt jedenfalls nicht weit über das neunte Jahrhundert, in dessen Verlauf die Benutzung bei Benedikt Levita und Hinkmar, vielleicht auch selbst noch die Herstellung der Pariser Handschrift, und gewiß der die Sammlung außer Verbindung mit dem Breviarauszug überliefernde Kodex bzw. der Archetyp fällt, setzen müssen. Ihre Aufnahme in die Epitome Parisiensis nötigt aber, selbst mit einer noch früheren Entstehungszeit zu rechnen, zumal wenn man erwägt, daß sie uns hier bereits in Gestalt ihrer Glosse, die doch nicht von vornherein der Sammlung beigefügt sein wird, und in einer der ursprünglichen Bestimmung fremden Verwendung begegnet. Es liegt dann nahe, den Versuch zu

in dem Texte von Theod. XVI $(2,47)$ nicht findet, nämlich Versagung des Besitzes von Sklaven und der 'licentia causas agendi vel militandi" für Juden und Heiden. Indessen Ausschluß der Juden und Heiden von jeder Militia hat ja bereits die Sammlung aus Theod. $(8,16 ; 10,21)$ gebracht: ingleichen ist der Titel 'Ne Christianum mancipium Iudaeus habeat' aufgenommen. Aber auch soweit der bezeichnete Rechtsinhalt der Simondischen Konstitution nicht in den Theod. XVI entlehnten Konstitutionen der Sammlung wiederkehrt, darf man für sicher balten, daß nicht gerade er, z. B. der Ausschluf der Juden von der Advokatur, den Sammler, dem es doch, nach dem überwiegenden Inhalt von Theod. XVI, um ganz andere Dinge zu tun war, zur Aufnahme des Gesetzes bestimmt haben wird. 
machen, aus dem Inhalt der Sammlung Momente zu ermitteln, die für die Bestätigung der Annahme ihrer Abfassung innerhalb der angegebenen örtlichen und zeitlichen Grenzen, oder am liebsten zu einer näheren Begrenzung verwertet werden können. Soweit ich sehe, versprechen diesen Dienst lediglich die Sätze, die unsere Sammlung mit Bezug auf den Paganismus und bestimmte Häresien und Häretiker einschließt. Sie enthält, wie wir sahen (vgl. S. 109), auch Konstitutionen, die sich gegen den Paganismus wenden. Hieraus darf man doch schließen, daß zur Zeit ihrer Veranstaltung das Heidentum noch nicht völlig abgetan ist, schwerlich mehr; denn der Judex, der, nach einem Gesetze vom Jahre 391 (10,10), auf Reisen oder in der Stadt in Andacht einen Tempel betritt und dafür mit Strafe bedroht ist, wird im Sinne der Sammlung, die den Text aufnimmt, schwerlich für einen Heiden, sondern für einen Amtsträger gelten müssen, der nach arianischem Vorbild auch vor den Altären der Heiden sein Haupt entblößen will. ${ }^{1}$ ) Wenn nun angenommen werden kann, daß unter den besonderen örtlichen Entstehungsverhältnissen, von denen sofort die Rede sein wird, Reste des Heidentums schwerlich sich in die zweite Hälfte des 6. Jahrhunderts hinübergerettet haben ${ }^{2}$, so ist damit auch für die Entstehungszeit der Sammlung ein äußerster Grenzpunkt gewonnen. Von den Häresien, die in den Konstitutionen genannt werden, kommt für unsere Frage kaum eine andere als das Pelagianum et Caelestianum dogma (Sirm. 6), von den Häretikern die Arianer, Manichäer und Priscillianisten (5, 59 u. 60; Sirm. 6), aber auch die Donatisten $\left(5,52\right.$ u. 6, 4) in Betracht. $\left.{ }^{3}\right)$ Die an den gallischen

1) So charakterisiert Agila in seinem Gespräche mit Gregor von Tours (Hist. Franc. 5, 44) den Arianer. - 2) Reste des Heidentums sind im burgundischen Gallien nicht über die erste Hälfte des 6. Jahrhunderts nachweisbar (vgl. S. $83^{2}$ ) - ${ }^{3}$ ) Es werden dann noch in zwei Konstitutionen genannt die Eunomiani, Macedoniani, Novatiani, Sabbatiani. Wie die Gesetze $(5,59$ u. 60) im Osten gegeben sind, so handelt es sich hier un Häretiker des Ostens oder um Ketzereien, die wenigstens für Gallien nicht in Betracht gekommen sein werden. Erwägt man, daß die beiden Konstitutionen neben ihnen die Arianer, Manichäer und Priscillianisten nennen, im übrigen aber ihre Sanktion gegen alle Ketzer richten, so kann man bestimmt annehmen, daß sie nicht um jener Häresien halber aufgenommen worden sind. Die Eunomianer waren übrigens nur eine Spielart der Arianer. 
Präfekten gerichtete Konstitution vom Jahre 425 bezeigt, daß der Pelagianismus um diese Zeit unter den Bischöfen Galliens Bekenner fand 1): aber auch noch später beschäftigt die Häresie das katholische Gallien ${ }^{2}$ ), bis sie dann das sogenannte Semipelagianische Dogma auslöste, das im Süden bedeutenden Anhang fand und mit dem 'Irrtum des Pelagius' auf dem Konzil von Orange vom Jahre 529 verurteilt wird. ${ }^{3}$ ) Erwägt man dies, so könnte der Veranstalter der Sammlung mit der Aufnahme der Sirmondischen Konstitution, neben der Absicht, ein nach Gallien und gegen eine Häresie auf gallischem Boden gerichtetes Gesetz darzubieten, noch im besonderen bezweckt haben, die kaiserliche Gesetzgebung gegen die pelagianische und Semipelagianische Lehre vorzuführen, was dann die Abfassung im südlichen Gallien und jedenfalls nicht lange nach jenem Konzil, das, soweit ich sehe, auf gallischem Boden die letzte Nachwirkung der pelagianischen Lehre darstellt, nahelegt. Entstehung im südlichen Gallien, und etwa zu gleicher Zeit verrät auch die Aufnahme der gegen die Arianer gerichteten Gesetze $(5,59$ u. 60$)$ : eine Bevölkerung mit starkem arianischen Einschlag gab es in Gallien doch nur auf dem Boden, wo die germanischen Stämme arianischer Konfession Fuß gefaßt hatten, also im Süden ${ }^{4}$ ) und insbesondere in den ehedem westgotischen Landschaften und in Burgund, und man mag vermuten, daß sich hier der Arianismus nicht lange nach Eintritt der Länder in das katholische System und insbesondere nach der Einverleibung in das Frankenreich, und kaum über die erste Hälfte des sechsten

1) Wie mir scheint (vgl. z. B. Realencykl. f. prot. Theol. ${ }^{3}$ XV 769; Zimmer Pelagius in Irland S. 29), ist dieses Zeugnis vielfach unbeachtet geblieben, was mit der irrigen Auffassung des Godofredus über die Sirmondischen Konstitutionen im allgemeinen und die unsrige im besondern ('farrago' ad 2, 64 sub a [p. 206]) in Verbindung stehen mag. Es ist berücksichtigt z. B. in Gallia christ. nov. III 1235 (n. 324). - 2) Vgl. Hefele, a. a. O. II 125. 291. 676. - s) MG. Concil. I, 46 sq. u. Jaffé Regesta ${ }^{2}$ n. 875. Nach Arnold (vgl. S. $79^{1}$ ) S. 327 gab es im 6. Jahrhundert in Frankreich noch eigentliche Pelagianer. Ältere gallische Kanonensammlungen enthalten gegen den Pelagianismus gerichtete Aktenstücke (vgl. Maassen [vgl. S. $100^{3}$ ] I 490. 496. 546). - 4) Vgl. Dahn, a. d. S. $73^{3}$ a. O. III 55: der Arianismus war im Frankengebiet unvertreten. 
Jahrhunderts hinaus, erhalten hat. Aber auch die Aufführung der Manichäer, einschließlich der Priscillianisten, mag man sie im Sinne des Urhebers der Sammlung mit ersteren identisch nehmen oder nicht (vgl. S. $79^{1}$ ), spricht für Entstebung dieser Art: denn es ist die Häresie, gegen die auf südgallischem Boden der westgotische Gesetzgeber vom Jahre 506 ankämpft (vgl. S. 79). Ich kann dann das Ergebnis der auf den Inhalt der Sammlung in Sachen des Paganismus und der Häresien gegründeten Erwägungen, hinsichtlich der Entstehungsverhältnisse unserer Sammlung, dahin zusammenfassen, daß sie in einem katholischen Staatswesen des südlichen Galliens, etwa in den ehedem westgotischen Landesteilen oder in dem alten Burgund, in der Zeit etwa des vierten oder fünften Jahrzehnts angefertigt worden ist. Ich verkenne nicht, daß es ein Ergebnis ist, das, soweit es das bereits gefundene Resultat näher präzisiert, nur ein gewisses Maß von Wahrscheinlichkeit beanspruchen kann, bin indessen schließlich auf einen Sachverhalt aufmerksam geworden, der hierfür nicht allein eine, wie mir scheint, erhebliche Verstärkung liefert, sondern auch das Material einer noch genaueren Datierung zu gewähren scheint; es ist der bisher nicht erörterte Umstand, daß die Sammlung zwei Gesetze $(5,52 ; 6,4)$ enthält, die sich gegen die Donatisten wenden, das eine $(6,4)$ sie insbesondere wegen des von ihnen gehuldigten Brauches der Wiedertaufe katholischer Konvertiten angreift. Ihre Aufnahme bedarf einer besonderen Erklärung, da nach unserer Überlieferung bekanntlich der Donatismus eine sozusagen afrikanische Häresie und vom Standpunkte Galliens jedenfalls durchaus fremdartige und überseeische Erscheinung ist, von der man meinen möchte, sie habe hier nicht Wurzel schlagen können. ${ }^{1}$ ) Man könnte darum zunächst dazu neigen, die Aufnahme der Konstitutionen damit zu erklären, $\mathrm{da \beta}$ es dem Urheber der Sammlung dabei um Belege der Ächtung nicht sowohl der Donatisten als vielmehr der von ihnen vertretenen Praxis

1) Es heifst zu dem S. 124 erwähnten Briefe des Avitus in der Ausgabe Sirmonds (vgl. Migne LIX 240d): at Donatistarum nomen unius fere Africae in qua natum erat finibus se continuit et vix unquam ad alias gentes pervasit, si Romam excipias, ubi Montenses vocabantur. 
der Wiedertaufe katholischer Konvertiten zu tun gewesen ist, weil diese Praxis von Arianern und sonstigen südgallischen Häresien (vgl. S. 95*) geübt wurde; der Sammler habe sich dieses Weges bedienen müssen, weil in Theod. in Sachen der Wiedertaufe ein direkt, z. B. gegen die Arianer, sich wendendes Gesetz nicht zur Verfügung stand. Gegen diese Erklärung spricht indessen das sehr nahe liegende Bedenken, daß der Urheber der Sammlung stark damit rechnen mußte, auf diesem Wege, richtiger Umwege sein angebliches Ziel durchaus zu verfehlen. $E_{8} \mathrm{muB}$ daher nach einer anderen Erklärung der auffallenden Erscheinung gesucht werden, und sie bietet sich in der Tatsache, da $B$ gerade unter den angenommenen und nur noch näher zu begrenzenden Entstehungsverhältnissen unserer Sammlung ein Anlaß vorlag, der Reaktion des Gesetzgebers gegen die Donatisten zu gedenken. Es handelt sich um einen Brief, den Avitus, der Erzbischof von Vienne im Königreich Burgund, zwischen 499, und 517 an Stephanus, Bischof von Lyon, gerichtet hat. ${ }^{1}$ ) Wenn wie in seinem Wirken überhaupt, auch in der literarischen Tätigkeit des Bischofs der Kampf des trinitarischen Glaubens gegen den Arianismus, der aber zur Zeit des Briefwechsels sich bereits zu einem Siege auszugestalten beginnt, im Vordergrunde steht ${ }^{2}$ ), so nimmt der genannte Brief eine eigenartige Stellung ein: er handelt nämlich von der ihm durch Stephanus gemeldeten 'raren' Erscheinung ('rara facies') des Eindringens von Donatisten und ihrer Lehre, die, von wer weiß welchem Winde, über das Meer hergeweht seien, auf dem fremden Boden aber nicht gedeihen dürfen, so daß alle in der Irrlehre Befangenen gestraft werden und die in Heimat und Sekte Fremden den Schranken des Erzbischofs fernbleiben müßten. Eine bessere Erklärung für die Aufnahme der beiden Konstitutionen als die, daß es unter dem Eindruck des in dem Briefe des Avitus berührten Ereignisses geschehen ist, wird sich schwerlich finden lassen. Da dieses aber

1) MG. Auct. antt. VI 2, 57. Der Brief gehört den Epistulae ad diversos an $(1,26)$. - $\left.{ }^{2}\right)$ Vgl. hierzu aus neuester Zeit Dahn, Die Könige der Germanen XI, 198f. u. v. Schubert (vgl. S. $82^{3}$ ) S. 26 f. Die von Avitus betriebene Konversion des Thronfolgers, Sigismund (zwischen 496 u. 499), vielleicht auch sein Regierungsantritt (516) fällt in die Zeit der Korrespondenz. 
-- unserer Überlieferung nach zu schließen, die von einer Fortexistenz der Sekte in Gallien nichts zu berichten weiß ebenso ephemer gewesen ist, wie es auffallend war, so könnte man annehmen, daß die Herstellung der Sammlung, der sie angehören, örtlich und zeitlich möglichst nahe an das Ereignis anzuknüpfen ist. Ergibt sich damit eine Begrenzung des bisher in Erwägung gezogenen Entstehungsgebietes, indem als solches lediglich das burgundische Königreich in Frage kommt, so läBt sich hinsichtlich der Entstehungszeit das bisher ermittelte Datum um so eher festhalten, als sich doch nicht vor dem Übergang ins fränkische Reich, im Jahre 534, eine radikale Katholisierung des Staatswesens erwarten läßt. Sehr einfach erklärt sich dann auch die Tatsache, daß der Sammlung ursprünglich eine Beziehung zur Lex Romana Visigothorum fehlte, aus dem Umstande, daß zur Zeit ihrer $A b-$ fassung die burgundische Lex Romana Anwendung fand, die ihrerseits in der Regelung der kirchlichen Verhältnisse äußerst enthaltsam war ${ }^{1}$ ) und die Herrschaft der alten Rechtsquellen, zumal wo sie Lücken ließ, nicht beeinträchtigen konnte..$^{2}$ Man wird dann aber auch nicht ganz abgeneigt sein, aus den Daten des Avitusbriefes sogar den Schluß zu wagen, daß die Sammlung gerade in Lyon ihre Heimat hat, und zwar insofern selbst mit einigem Recht, als hier nachweislich die Quellen, aus denen sich das Produkt zusammensetzt, Theod. und die Sirmondische Sammlung, zu finden waren ${ }^{3}$ ) und im ausgehenden Altertum die römischen Rechtsbücher zum Gegenstande literarischen Betriebs geworden sein mögen. ${ }^{4}$ )

1) Vgl. Dahn, Die Könige der Germanen XI 232 u. 233. - ${ }^{2}$ ) Vgl. Brunner, Deutsche Rechtsgesch. ${ }^{2}$ I, 509. - ${ }^{3}$ ) Vgl. Mommsen p. XXXVIII u. XXXIX; Traube, p. II u. III. - ${ }^{4}$ ) Trau be, Einleitung in die Lat. Philologie d. Mittelalters (Vorles. u. Abhandl. II) S. 126, meint, daß Lyon nicht nur durch die Überlieferung juristischer Literatur wichtig geworden sei, sondern sogar eine Hochschule der Rechtswissenschaft besessen habe. Dies bleibt zu untersuchen. 